\title{
A Simulation Study of the Impact of LP EGR on a Two-Stage Turbocharged Diesel Engine
}

\author{
P. Gautier' ${ }^{1}$ A. Albrecht' ${ }^{1}$ A. Chasse ${ }^{1}$, P. Moulin ${ }^{1}$, A. Pagot ${ }^{1}$, L. Fontvieille ${ }^{2}$ and D. Issartel ${ }^{2}$ \\ 1 Institut français du pétrole, IFP, 1-4 avenue de Bois-Préau, 92852 Rueil-Malmaison Cedex - France \\ 2 Renault, 13-15 Quai Le Gallo, 92109 Boulogne-Billancourt Cedex - France \\ e-mail: pierre.gautier@ifp.fr - antoine.albrech+@ifp.fr - alexandre.chasse@ifp.fr - philippe.moulin@ifp.fr - alexandre.pagot@ifp.fr \\ laurent.fontvieille@renault.com - david.issartel@renault.com
}

Résumé - Étude par simulation de l'impact de l'EGR BP sur un moteur Diesel à double étage de suralimentation - Depuis quelques années, les projets de développement moteur ont pour obligation de relever des défis de plus en plus difficiles : réduire les émissions de polluants à la source tout en maintenant, voire en réduisant la consommation de carburant. Pour essayer de résoudre ce problème, de nombreuses technologies ont été étudiées et certaines permettent d'offrir au moins une partie de la solution. Parmi celles-ci, l'utilisation de turbocompresseurs semble un des meilleurs compromis à l'heure actuelle. Plusieurs technologies de turbocompresseurs et de boucles d'air associées peuvent ensuite être utilisées et, parmi celles-ci, la double suralimentation série semble être l'une des plus prometteuses.

Allant de pair avec ces systèmes de suralimentation, les circuits d'EGR restent le meilleur compromis coût/efficacité à court et moyen terme pour respecter les normes d'émissions de polluants. Par ailleurs, les circuits d'EGR haute pression ne sont plus l'unique solution pour recirculer les gaz d'échappement vers les cylindres, puisque l'utilisation de plus en plus répandue de filtres à particules permet de réduire l'un des inconvénients majeurs de l'EGR basse pression : la fiabilité du compresseur et du refroidissement de l'air de suralimentation.

Dans ce contexte, il est alors difficile d'évaluer de manière intuitive l'impact de chaque boucle d'air envisageable sur les performances moteur et les conséquences sur les stratégies du contrôle moteur associé. Il devient alors nécessaire d'utiliser des outils de plus en plus avancés, comme la simulation en général, et la simulation système en particulier.

Dans cet article, nous présentons la manière dont la simulation système peut être mise à profit pour la compréhension de problèmes technologiques aussi bien que ceux liés au contrôle moteur. Cette approche est illustrée à travers l'étude de l'impact de l'EGR BP dans le cas spécifique d'un moteur Diesel à double étage de suralimentation. En effet, les impacts sur l'architecture de la boucle d'air ainsi que sur les performances moteur sont présentés et analysés à l'aide de résultats de simulation obtenus à partir d'un simulateur du même moteur, mais disposant soit d'un circuit EGR haute pression, soit d'un circuit EGR basse pression. En parallèle, les spécificités du contrôle pour ce type de moteur à double étage de suralimentation sont rappelées. L'impact de l'utilisation d'un circuit d'EGR basse pression sur ces stratégies de contrôle est ensuite analysé et une solution pour adapter ces lois de contrôle est finalement proposée.

\footnotetext{
Abstract - A Simulation Study of the Impact of LP EGR on a Two-Stage Turbocharged Diesel Engine - Current engine development projects have to face crucial challenges: raw pollutant emission reduction while maintaining or even reducing the engine fuel consumption. To solve this issue, several technologies have been studied and some can offer part of the solution. Among these
} 
technologies, turbochargers provide one of the best trade off. Different turbocharging technologies can be used as well as different air path layouts, but one particularly promising technology relies in the Two-Stage series turbocharging.

Coupled to turbocharging devices, and despite the recent development in $N O_{x}$ after-treatment systems, EGR remains a cost-effective solution to respect current and future emissions standards. Thanks to the widespread use of Diesel Particulate Filters, High Pressure EGR is no longer the only efficient solution to provide exhaust gas to the cylinders, in so far as one of the main drawbacks of Low Pressure EGR compressor and air intake cooler reliability - is reduced.

In this context, it is difficult to assess intuitively the impact of the different possible air system configurations on the engine performance, and the consequences on the associated control strategies. It is therefore necessary to use advanced tools, such as simulation in general and engine system simulation in particular.

In this paper, we present the way engine system simulation can help in the understanding of technological issues as well as control issues. The approach is illustrated by the study of the impact of Low Pressure EGR in the specific case of a Two-Stage Turbocharged Diesel Engine. Indeed, the impact on the air path layout and on the engine performances are presented, and comparisons between simulation results of the same engine with a High Pressure or a Low Pressure EGR circuit are analyzed. In parallel, some specificities of the control strategy of a Two-Stage Turbocharged Diesel engine are discussed. The impact of a LP EGR circuit on the control laws is analyzed and a solution to adapt the strategies is finally proposed.

\section{ABBREVIATIONS}

$C_{p} \quad$ Constant Pressure Specific Heat

CRL Connecting Rod Length

DPF Diesel Particulate Filter

TS Two-Stage

$E P D_{X} \quad$ Exhaust Pressure Drops, depending on mass flow

EGR Exhaust Gas Recirculation

exh. Exhaust

FAER Fuel Air Equivalence Ratio

HP High Pressure

IMEP Indicated Mean Effective Pressure

int. Intake

$I P D_{X} \quad$ Intake Pressure Drops, depending on mass flow

$L P \quad$ Low Pressure

$\dot{M}, \quad$ Mass Flow

$P @ H P T I \quad$ Pressure at High Pressure Turbine Inlet

$P R_{c} \quad$ Compressor Pressure Ratio

$P R_{t} \quad$ Turbine Pressure Ratio

$P_{x} \quad$ Absolute Pressure

$Q_{x} \quad$ Mass Flow of $x$

$S F C \quad$ Specific Fuel Consumption

STAFR Stoechiometric Air Fuel Ratio

T@HPCO Temperature at High Pressure Compressor Outlet

$T_{X} \quad$ Temperature

URS User Requirement Specifications

VGT Variable Geometry Turbine

WG Waste Gate

$\gamma_{x} \quad$ Ratio of Specific Heats

$\lambda \quad$ Air Fuel Equivalence Ratio

$\eta_{\text {comp }} \quad$ Compressor Efficiency

$\eta_{\text {turb }} \quad$ Turbine Efficiency

\section{INTRODUCTION}

\section{Technology Context}

Due to severe raw emission constraints, one major aspect of new Diesel engines is their capacity to provide fresh air to the system even with high Exhaust Gas Recirculation (EGR) rates. To that purpose, more or less complex air intake systems have been studied, among which turbochargers have met a great interest. Indeed, they enable the extension of the engine operating range with high EGR levels (required performance), but also increase the power production, by allowing larger quantities of air in the cylinder at high engine speed. Among the various turbocharged architectures that have been proposed, the Two-Stage (TS) turbocharger is a promising one (see for example [1] for the description of such a system, and [2-5] for additional examples).

Furthermore, thanks to the widespread use of Diesel Particulate Filters (DPF) on recent Diesel engines, one of the main drawbacks of Low Pressure (LP) EGR systems (compressor and air intake cooler reliability) has been reduced. Also, this technology presents a lot of additional well known interests [6-10] in traditional Simple-Stage Turbocharged Diesel engines, like:

- the increase of intake $\mathrm{CO}_{2}$ concentration without diminishing the oxygen-to-fuel ratio, and while keeping the air intake temperature quite low and thus providing important $\mathrm{NO}_{\mathrm{x}}$ reduction without increasing opacity;

- the improvement of cylinder-to-cylinder charge dispersion;

- the shift of the compressor operating points further from the surge line;

- the improvement of transient response time thanks to the increase of energy available at the turbine. 
This system also brings the drawback of increasing the engine exhaust back pressure in the EGR operating zone. This effect is explained by two different phenomena: with LP EGR more air flow goes through the turbine and the particulate filter, and the use of the exhaust throttle increases the pressure drop through the exhaust line. Another drawback comes from the fact that hot gas are fed into the compressor, which results in an increase of the compressor wheel temperature and may damage this component. This inconvenient can be solved by the integration of an efficient cooling system on the LP EGR circuit.

The purpose of this article is to study the association of TS turbocharging and LP EGR. From the short discussion above, it appears that the interactions between these two systems are complex and difficult to assess intuitively. Particularly, the engine exhaust pressure and the cooling configuration need to be considered in detail. In addition to these topics, the control aspects associated to these technologies require some specific developments. A global approach based on system simulation tools is proposed in order to address both architecture and control issues.

\section{Simulation Context}

Improving the simulation support in engine development projects is a very attractive way to reduce cost and duration of such projects while increasing the deliverable quality as schematized in Figure 1. Indeed, due to complexity of the new engine solutions, the systems become more and more complex to design, and also to control. As a double consequence, simulation takes a more and more important place in that kind

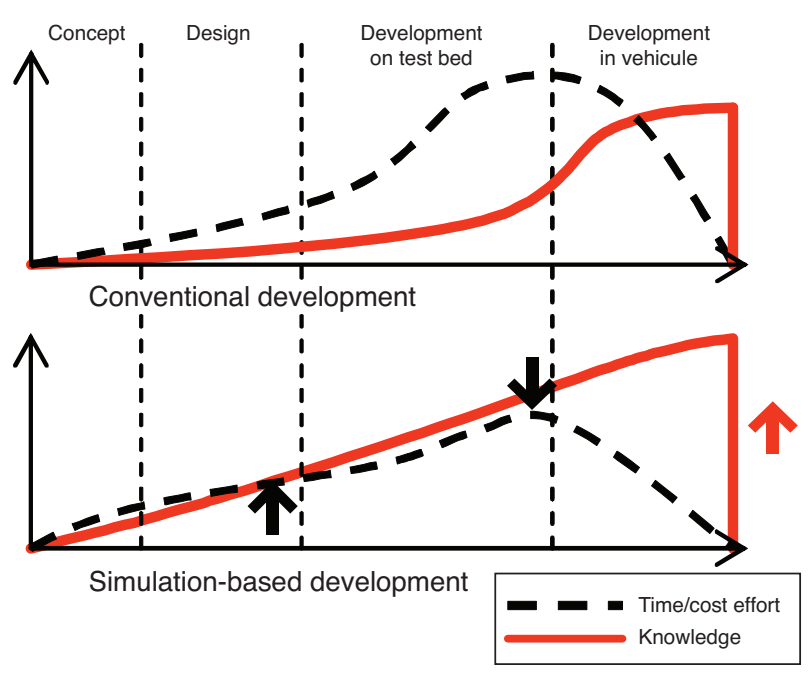

Figure 1

Simulation extensive use context.

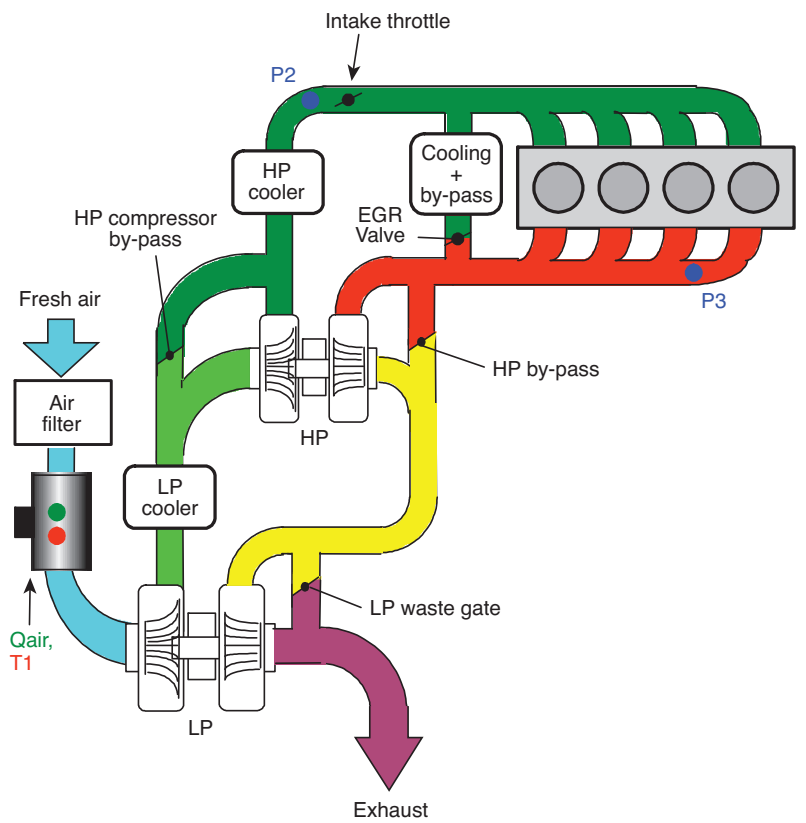

Figure 2

Reference Two-Stage Turbocharger Diesel Engine set up fitted with HP EGR (Simulator 1 in Tab. 2).

of engine development projects. Finally, engine system simulation, thanks to its wide range of possible applications, can be used at a lot of different steps in such kind of projects.

Among the many possible uses of engine system simulation in an engine development project (see [11] or [12] for examples), we present in this article the use of engine system simulation to evaluate the impact on engine performances and on the control strategies of a Low Pressure EGR circuit in the specific case of a Two-Stage Turbocharged air path.

To that purpose, the simulator of a 2,0L 4-cylinders Diesel engine fitted with High Pressure (HP) EGR (cf. Fig. 2 for the air path architecture and Tab. 1 for the engine characteristics) and developed during an IFP and Renault project (presented in [13]), and already validated on a wide range of operating steady state points and transients, has been used as the starting point and the reference for this study. To evaluate the importance of the air intake cooling system in such air path layouts and by implementing only a few slight modifications on this reference simulator, 3 additional simulators have been developed (see Tab. 2 for the specificity of the simulators) and tested in several conditions.

This article is divided as follows. In a first part, the reference engine simulator (TS turbocharger and HP EGR) is presented quickly and some results are given to validate the accuracy of this simulator. Then, we present the modifications made on the reference engine simulator to obtain the simulators used to evaluate and compare Low Pressure and 
TABLE 1

Engine characteristics (M9R - Two-Stage Turbocharged Diesel Engine)

\begin{tabular}{c|c|c}
\hline \multicolumn{3}{c}{ Engine characteristics } \\
\hline Number of cylinders & - & 4 \\
\hline Bore & $\mathrm{mm}$ & 84 \\
\hline Stroke & $\mathrm{mm}$ & 90 \\
\hline CRL & $\mathrm{mm}$ & 143.5 \\
\hline Cubic capacity & 1 & 2.0 \\
\hline
\end{tabular}

TABLE 2

Four versions of the engine simulator

\begin{tabular}{|c|c|}
\hline Simulator & Version \\
\hline \multirow{2}{*}{1} & - HP and LP air intake coolers \\
\hline & • HP EGR Circuit \\
\hline \multirow{2}{*}{2} & - HP air intake cooler \\
\hline & • HP EGR Circuit \\
\hline \multirow{2}{*}{3} & - HP and LP air intake coolers \\
\hline & - LP EGR Circuit \\
\hline \multirow{2}{*}{4} & - HP air intake cooler \\
\hline & - LP EGR Circuit \\
\hline
\end{tabular}

High Pressure EGR circuits in the Two-Stage Turbocharging context. In the last part, the specificities of the control strategies for Two-Stage Turbocharged Diesel engines are presented, followed by a discussion on the impact of LP EGR on the control strategies.

\section{TWO-STAGE TURBOCHARGER DIESEL ENGINE SIMULATOR WITH HP EGR CIRCUIT SET UP AND VALIDATION}

As explained in the introduction, a previous project allowed us to start this study from a validated simulator of the $2.0 \mathrm{~L}$ 4-cylinders TS Turbocharger Diesel Engine with a High Pressure EGR circuit. A picture of the sketch of the simulator in the AMESim environment is available in Figure 3, and a few part of the validation results of the simulator are available in Figures 4, 5 and 6 for steady state results, and in Figure 8 for transient results.

This simulator was built using elements of the following libraries:

- IFP-Engine library: for all the elements of the air path and the fuel path (turbochargers, pipes, coolers, manifolds, injectors and combustion chambers) in blue in Figure 3;
- mechanical library: for the inertias of the two turbochargers - in green in Figure 3;

- thermal library: for the heat exchanges on the exhaust manifold and for the cylinder wall exchanges - in brown in Figure 3.

The combustion model is a model based on the CHMELA approach [14], improved at IFP to be able to take into account the ignition delay and the effect of burnt gas on heat flow rate [15]. A fixed step solver is used to perform the simulations. The computational time of this simulator is lower than 10 times the real time.

For additional information about the elements of the libraries, please refer to [16] for all the AMESim libraries, and to $[17,18]$, for the libraries developed at IFP.

Figures 4, 5 and 6 show the good correlation between engine simulator results and real engine test bed measurements. This campaign validates thus the engine simulator performance in steady state conditions.

To complete this validation, transient tests have also been performed with the simulator and then compared to the vehicle results. Figures 7 and 8 present a comparison between vehicle and simulation results on the NEDC cycle.

If we extract from the NEDC cycle, the EUDC cycle (the part in the doted frame in Fig. 7), we can notice in Figure 8 the good correlation between simulation results and vehicle measurements on these values, notably in terms of dynamical behaviour. This figure shows how representative of the real engine the engine simulator was at the end of the control design study.

For more details about the set up of this simulator, the hypothesis and the context of the study or for additional results, please refer to [13].

\section{LP EGR IMPACT ON THE SYSTEM: SET UP OF THE ADDITIONAL SIMULATORS}

As mentioned in the introduction, 3 additional simulators have been set up to study the impact of LP EGR on the engine performances in the specific case of Two-stage turbocharging. In Figure 9, the air path layouts of these engines are displayed.

The 3 additional simulators layouts are:

- air path 2: HP EGR circuit - no LP air intake cooler: for this simulator, the HP EGR circuit is conserved, but the LP ER cooler is removed form the air path;

- air path 3: LP EGR circuit - one LP and one HP air intake cooler: for this third simulator, a LP EGR circuit is implemented. As usual, this inlet of this circuit is placed behind the after-treatment system (modelled by a pressure drop and a heat transfer), and the outlet is placed between the air intake filter and the LP compressor. The two air intake coolers are conserved; 


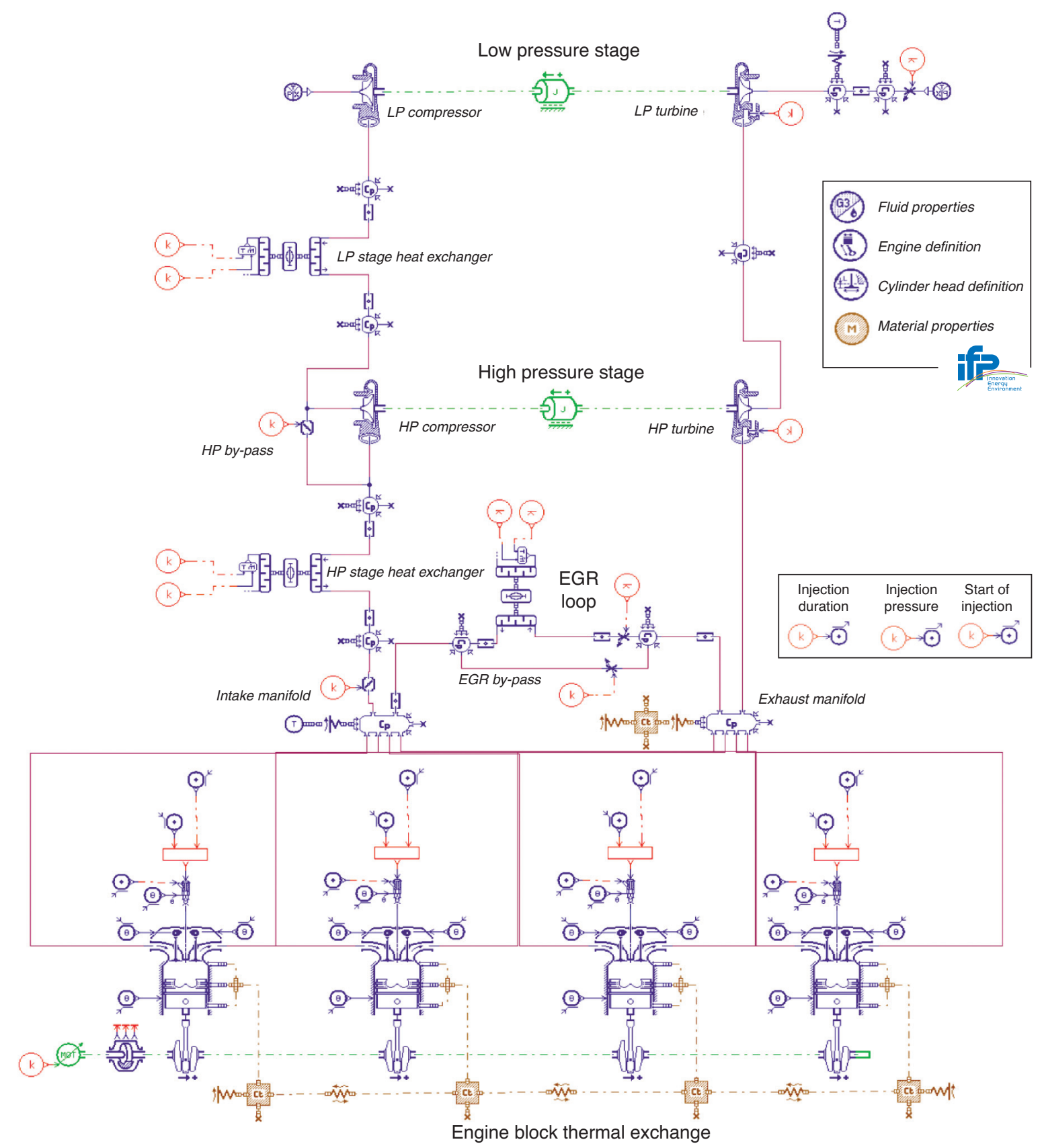

Figure 3

AMESim diagram of the Two-Stage Turbocharged Diesel Engine simulator fitted with HP EGR.

- air path 4: LP EGR circuit - no LP air intake cooler: for this last simulator, the LP EGR circuit is conserved, but the LP air intake cooler is removed.

For each simulator, the combustion is not modified, as well as the maps of the compressor and the turbines or any of the pipes, except those between the LP compressor and the LP air intake cooler (to maintain the same volume between the two compressors).
Finally, 4 engine simulators have been studied (see Tab. 2 for the complete list of engine simulators), the main differences being:

- the use of a HP or a LP EGR circuit;

- the use of one LP and one HP coolers or only one specific HP cooler.

The LP EGR circuit design is based on Renault's User Requirement Specifications, and pressure drops of the global 

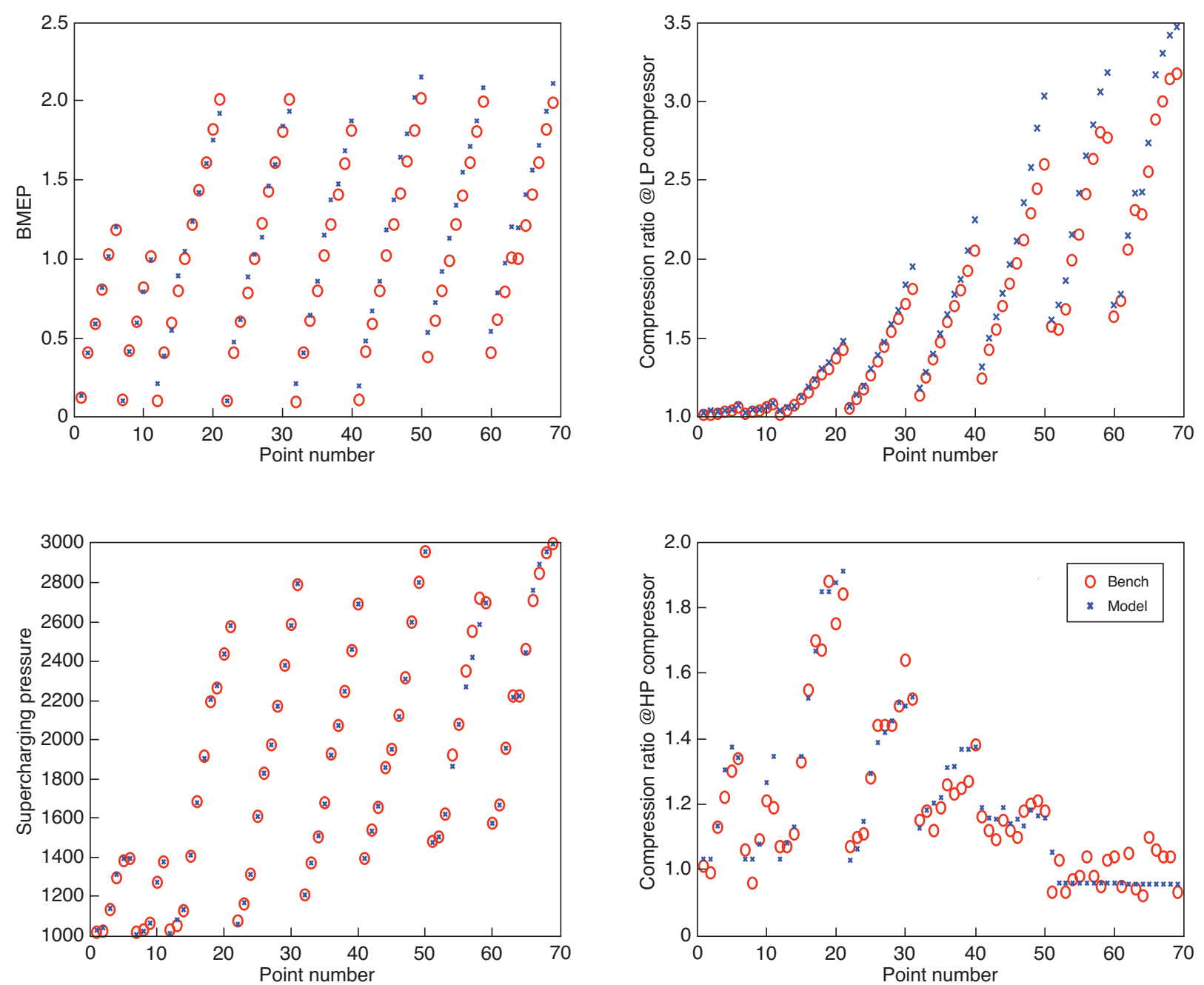

Figure 4

Model/bench steady state comparisons for load variations at different engine speeds (1000 rpm to $4500 \mathrm{rpm}$ by $500 \mathrm{rpm}$ steps): BMEP (top left), C.R.@LP compressor (top right), Pressure @intake manifold (bottom left) and C.R.@HP compressor (bottom right).

LP EGR circuit are calibrated according to values based on Renault and IFP's experience. It thus means that no hard EGR circuit results have been used to calibrate it. A picture of the LP EGR circuit in the AMESim environment is available in Figure 10.

The EGR circuit is composed of a cooler, a LP EGR throttle to control the amount of EGR for low EGR rates, and a throttle on the exhaust line for higher EGR rates. This model is very simple, but allows to represent the main phenomena of the system.

\section{LP EGR IMPACT STUDY BY SIMULATION}

\subsection{Validation of the Reference Simulator}

The simulation study has been focused on 6 steady state operating set points extracted from the EGR zone (BMEP ranging from $15 \%$ to $79 \%$ of the maximum BMEP and engine speed ranging from $33 \%$ to $50 \%$ of the maximum engine speed). A first work was to check the validity of the reference simulator on these 6 set points. The simulation conditions were:

- closed loop control on supercharging pressure;

- closed loop control on the air mass flow;

- open loop control on the fuel mass flow.

As seen in Figure 11, the results of simulator 1 (reference simulator) present a good correlation with the measurements realized on the real engine, which implies a pretty good confidence in the ability of the engine simulators to be representative of the different variations done during the study on these 6 set points.

After this first verification, the numerical campaign has been simulated. This campaign has been split into two main phases:

- relative comparison between the 4 different simulators on the 6 set points; 

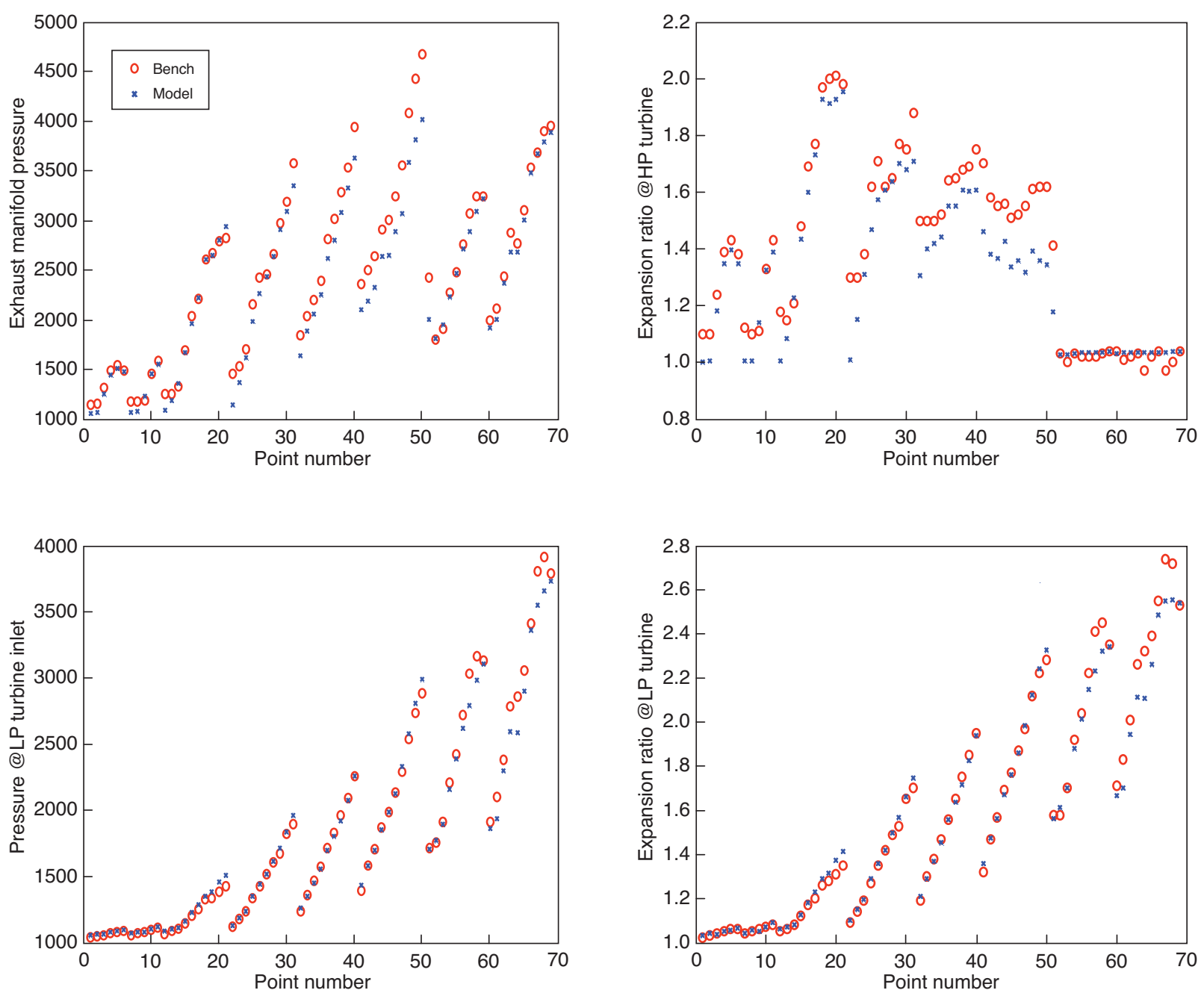

Figure 5

Model/bench steady state comparisons for load variations at different engine speeds (1000 rpm to 4500 rpm by 500 rpm steps): Pressure @ exhaust manifold (top left), ER@HP turbine (top right), Pressure @LP turbine inlet (bottom left) and ER@LP turbine (bottom right).

- specific study with simulators 2 and 4 on a cooler efficiency variation, on atmospheric condition variations, on EGR mass flow variations, and on a supercharging pressure variation.

\subsection{LP EGR Impact Study: Comparison of the 4 Simulators}

First, the different air path layouts have been compared to evaluate their respective advantages and drawbacks. For this first campaign, the simulation conditions were:

- closed loop control on supercharging pressure;

- closed loop control on IMEP (by adjusting the injected mass of fuel);

- closed loop control on fuel air equivalence ratio (by adjusting the EGR mass flow);
- no limitation on temperature at compressor outlet;

- no limitation on exhaust pressure.

In Figure 12, one can observe the results on four important values:

- first, as expected, the HP compressor downstream temperature increases due to the combine effect of a higher temperature of gas with EGR at HP compressor inlet and a double compression of these gas (once in the LP stage, and once on the HP stage). The risk here is a temperature that gets higher than a maximum value tolerated by the compressor materials (see red line in the figure). We can notice the importance of the LP air intake cooler in this figure, notably on the most loaded set point;

- the second effect of LP EGR that can be observed on these simulations is the increase of exhaust pressure (pressure at HP turbine inlet). Indeed, if we schematized 

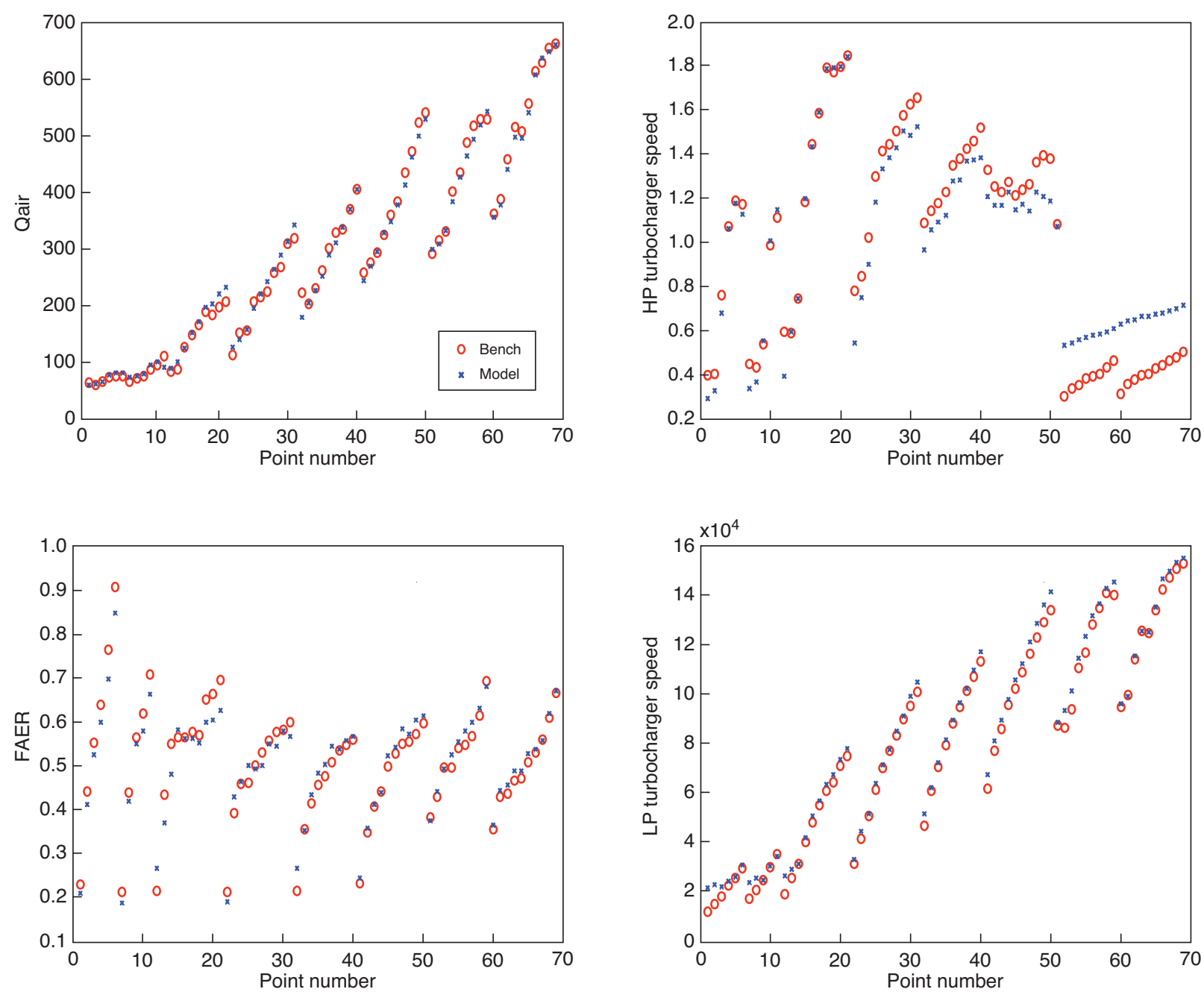

Figure 6

Model/bench steady state comparisons for load variations at different engine speeds ( $1000 \mathrm{rpm}$ to $4500 \mathrm{rpm}$ by $500 \mathrm{rpm}$ steps): air mass flow (top left), HP turbocharger speed (top right), FAER (bottom left) and LP turbocharger speed (bottom right).

the engine layout as presented in Figure 13, boosting can be seen as a whole device supplying boost pressure and having a negative effect on engine back pressure. In case of multi-stages supercharging device, the efficiency is a combination of wheels' efficiencies, pressure drops between the components and heat exchange in case for example of series architecture with intercooler between the two compressor stages. When regarding the effect of EGR, above all, it modifies flows and gas properties in the different components of the air loop. These different effects on the engine back pressure $\left(P_{3},\right)$ are analyzed for a fixed boost pressure target $\left(P_{2},\right)$.

The analysis is based on the balance between compression stage and expansion stage powers that are equal to:

$$
\dot{M}_{\text {int }} \times C p_{\text {int. }} \times\left(T_{2}-T_{1}\right)=\dot{M}_{e x h} \times C p_{\text {exh }} \times\left(T_{3}-T_{4}\right)
$$

With the schematic view presented in Figure 13, we are only considering HP EGR or LP EGR. It means that the exhaust mass flow in the turbocharging device is equal to the intake mass flow plus the fuel flow. We consider here, that this is still right in the case of LP EGR, so:

$$
\dot{M}_{\text {exh. }}=\dot{M}_{\text {int }} \times\left(1+\frac{1}{\lambda \times S T A F R}\right)
$$

Considering the isentropic efficiency of each stages we have:

$$
\begin{aligned}
& \left(T_{2}-T_{1}\right)=\frac{1}{\eta_{\text {comp }}} \times T_{1} \times\left(\left(\frac{P_{2}}{P_{1}}\right)^{\frac{\gamma_{1}-1}{\gamma_{1}}}-1\right) \text { and } \\
& \left(T_{3}-T_{4}\right)=\eta_{\text {turb }} \times T_{3} \times\left(1-\left(\frac{P_{3}}{P_{4}}\right)^{\frac{1-\gamma_{3}}{\gamma_{3}}}\right)
\end{aligned}
$$




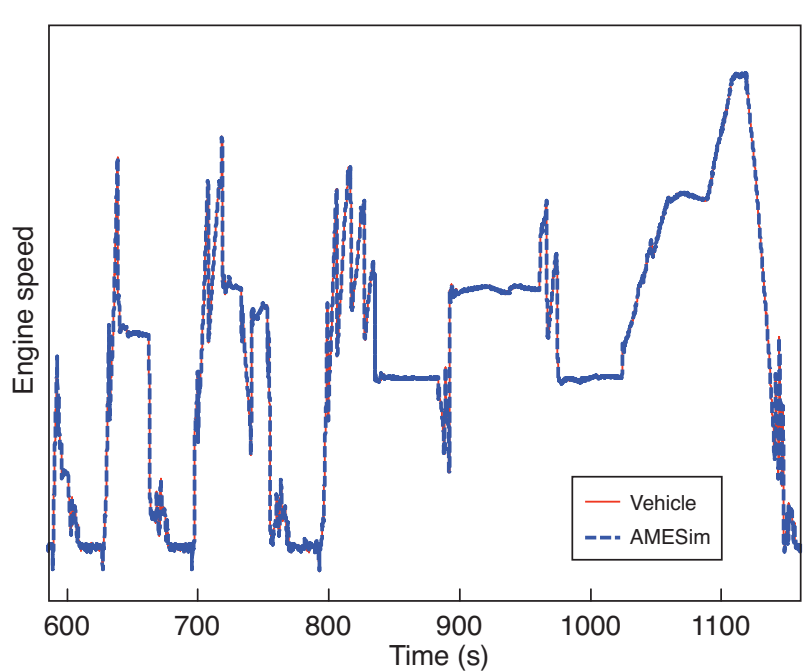

Figure 7

Engine speed during a NEDC cycle.
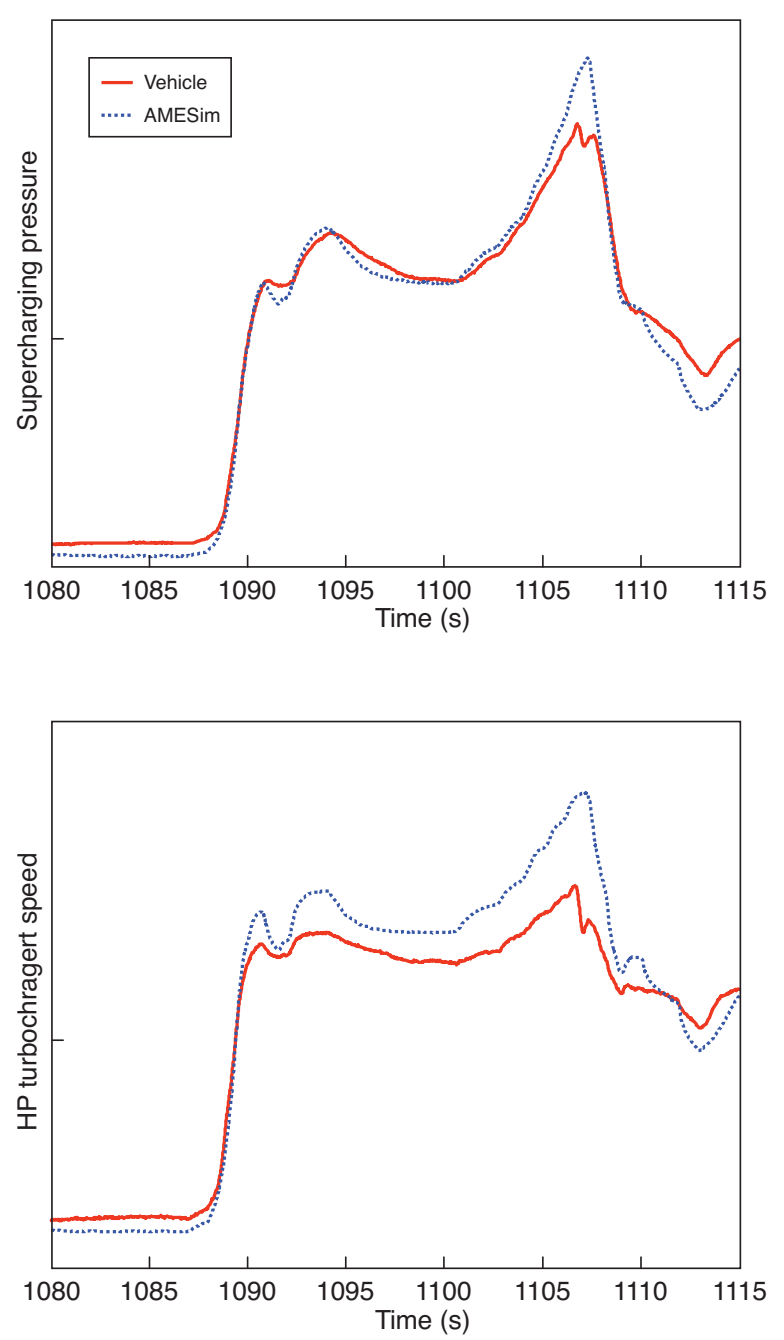

The different pressures can be computed only considering the pressure drops, $P_{0}$ (atmospheric pressure), the target of boost pressure $\left(P_{2}\right.$, ) and the penalty for the engine $\left(P_{3}\right.$,). Finally, the engine back pressure can be computed as follows:

$$
\begin{aligned}
& P_{3}=\left(P_{0}+E P D_{2}+E P D_{3}\right) \times \\
& \left(1-\frac{1}{\eta_{\text {comp }} \eta_{\text {turb }}} \times \frac{C p_{\text {int }}}{C p_{\text {exh }}} \times \frac{T_{1}}{T_{3}} \times \frac{\left(\frac{P_{2}+I P D_{1}}{P_{0}-I P D_{2}}\right)^{\frac{\gamma_{1}-1}{\gamma_{1}}}-1}{1+\frac{1}{\lambda \times S T A F R}}\right)^{\frac{\gamma_{3}}{1-\gamma_{3}}}+E P D_{1}
\end{aligned}
$$

It is then easy to evaluate the effect of LP EGR compared to HP EGR regarding each term of the previous equation (Eq. (4)). The most relevant ones are explained here after:

- Pressure drops: whatever the components, if the mass flow increases so does pressure drop. Consequently LP
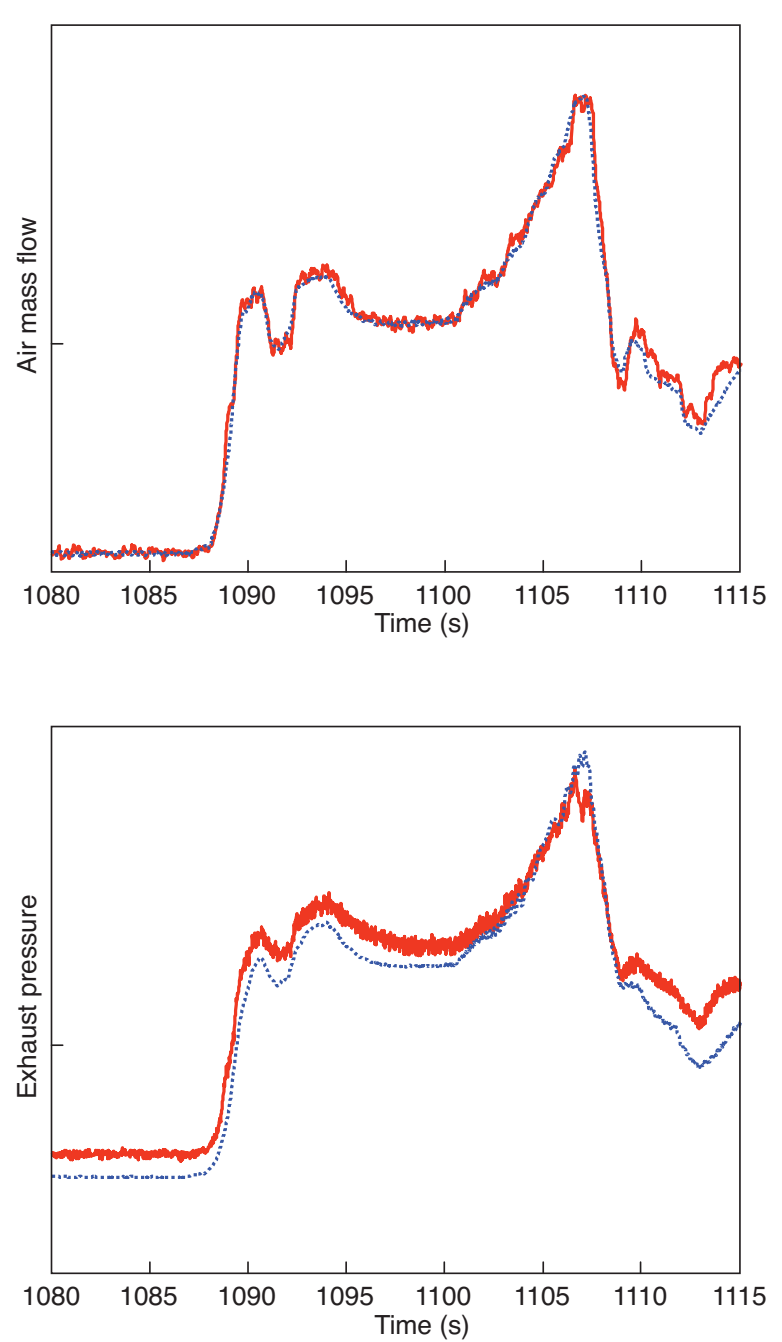

Figure 8

Comparison between vehicle results and simulation results on a transient extracted from a NEDC cycle: supercharging pressure (top left), air mass flow (top right), HP turbocharger speed (bottom left) and exhaust pressure (bottom right). 


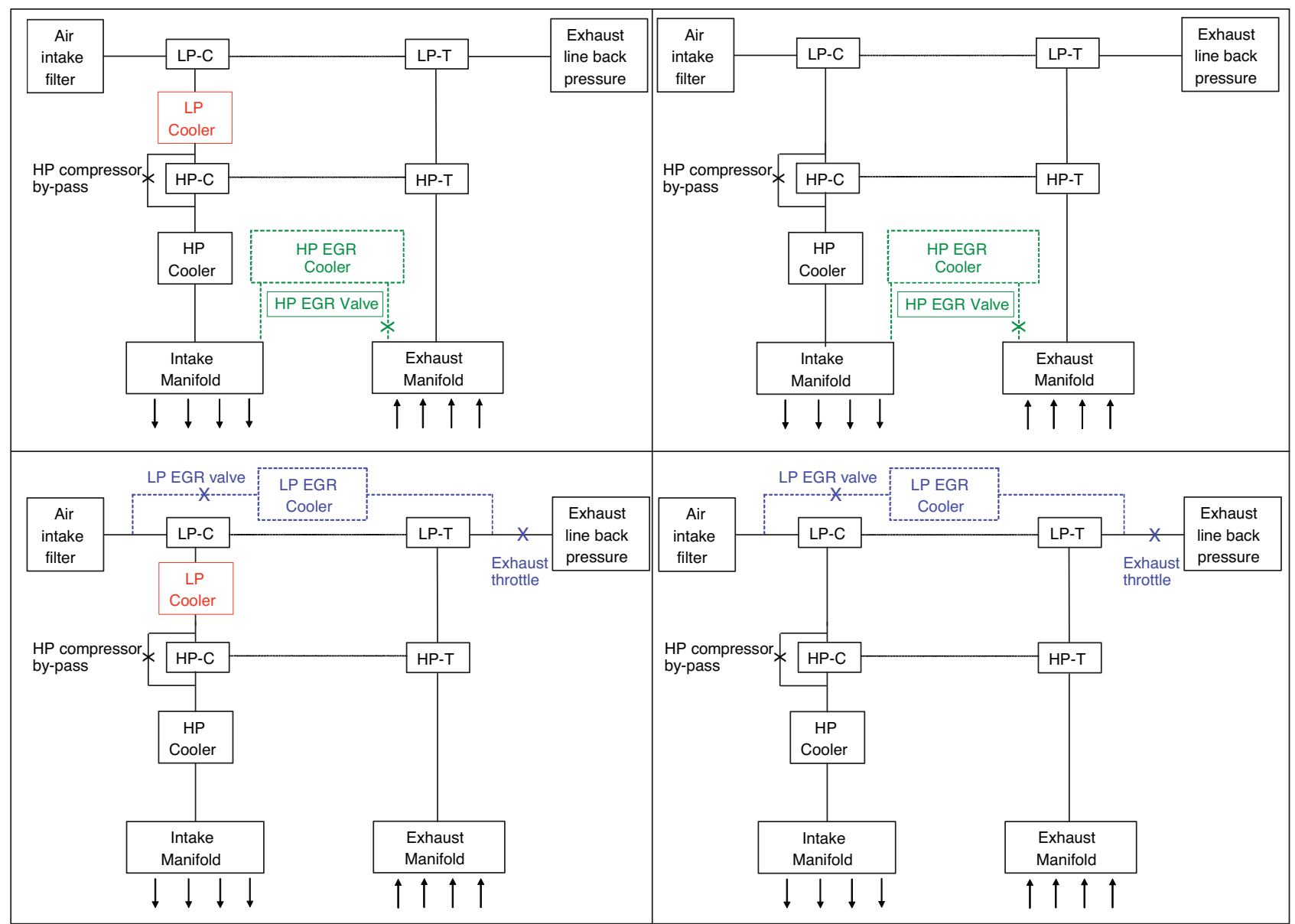

Figure 9

Two-Stage Turbocharger air path - HP EGR circuit with two air intake coolers (top left) and HP EGR circuit with only the HP air intake cooler (top right) - LP EGR circuit with two air intake coolers (bottom left) and LP EGR circuit with only the HP air intake cooler (bottom right).

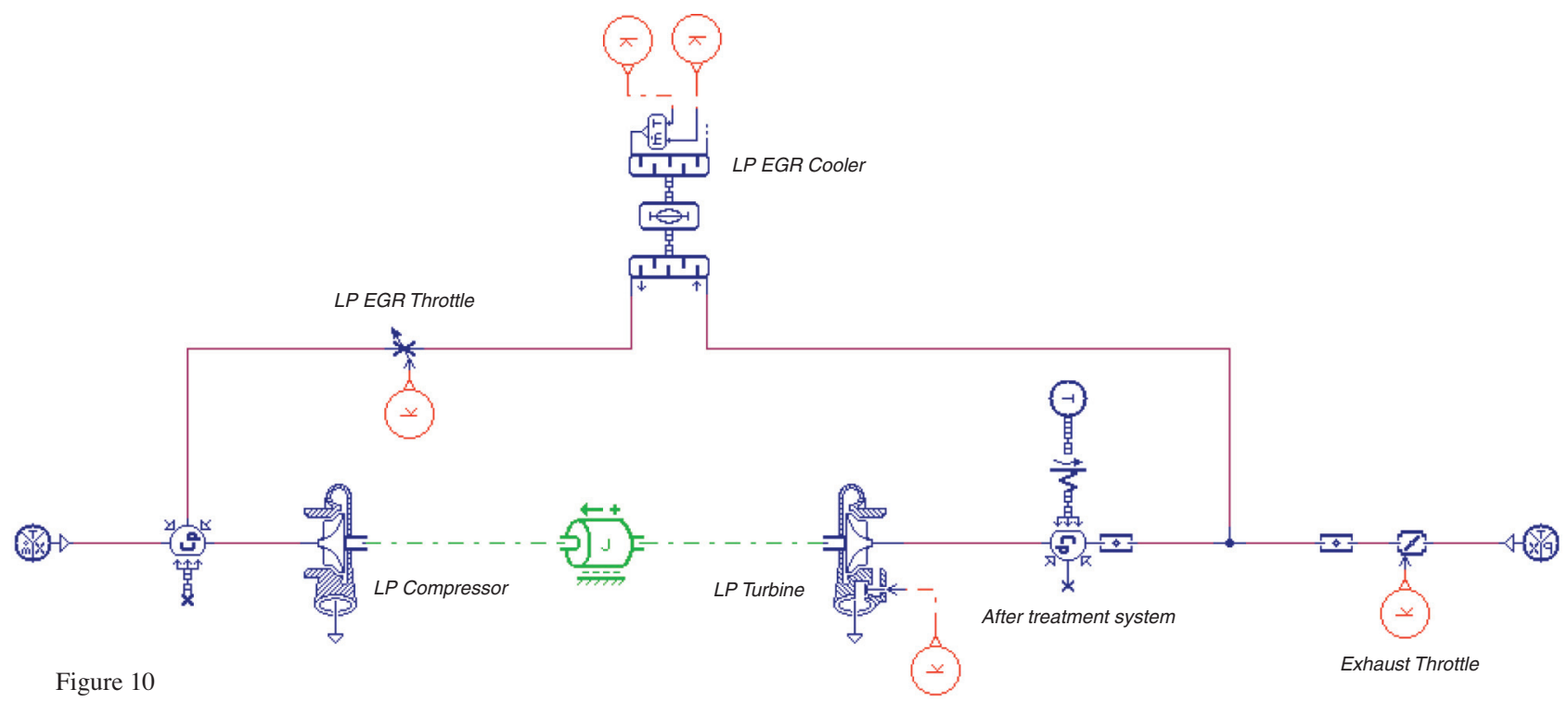

AMESim diagram of the LP EGR circuit. 

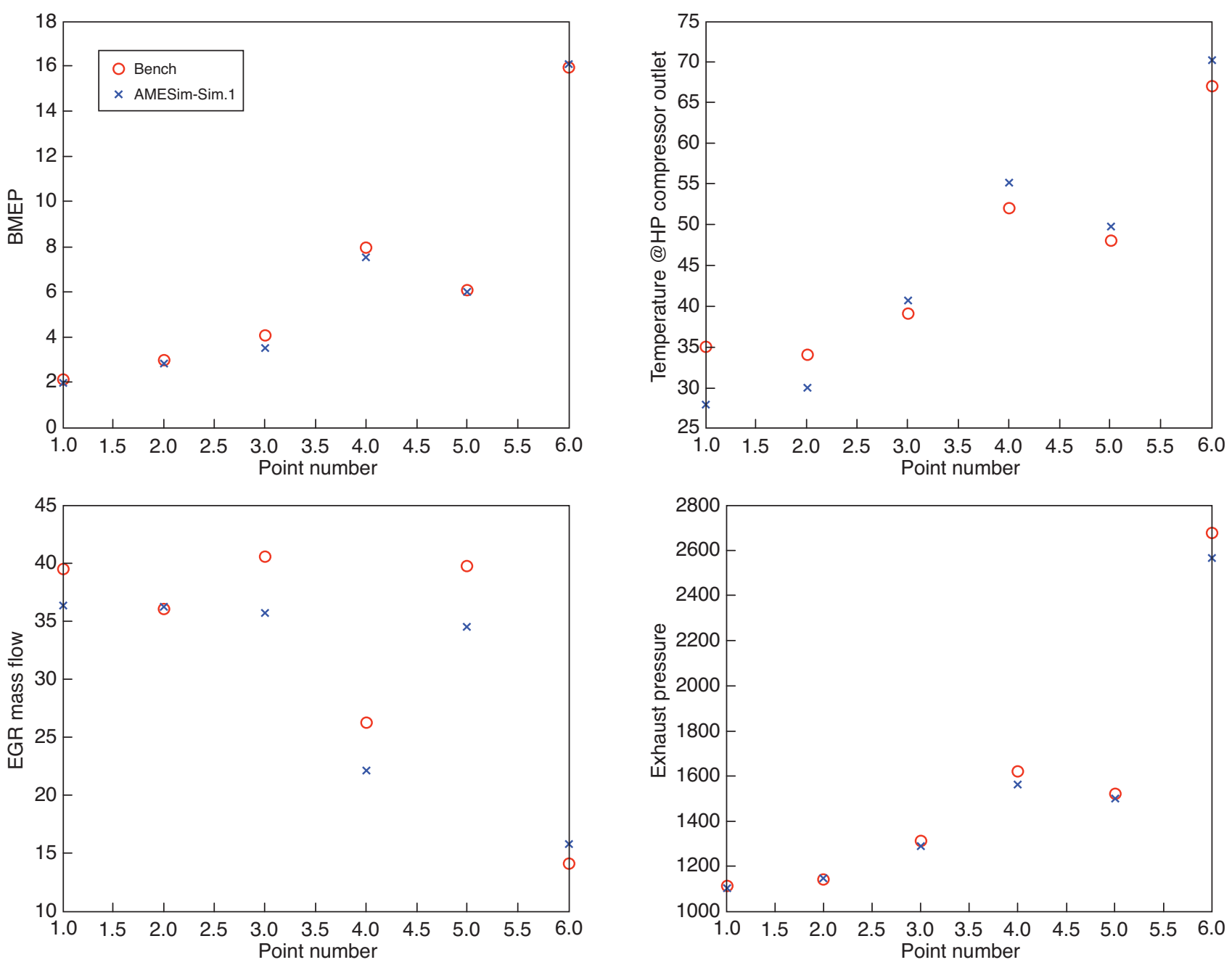

Figure 11

Comparison between bench results and simulation results on a the 6 steady state set points extracted from the EGR zone: BMEP (top left), T@HP compressor downstream (top right), EGR mass flow (bottom left) and exhaust pressure (bottom right).

EGR will have negative effect on IPD1, EPD1 and EPD2 and consequently on engine back pressure.

- T1: LP EGR will increase gas temperature on the compression stage which will increase the power demands on the exhaust side of the turbocharging device Consequently, $\mathrm{P}_{3}$, will also be penalized by LP EGR.

- Turbocharger device efficiencies: the highest the efficiency is the lowest the engine back pressure is. LP EGR effect on the turbocharging device depends on the matching and the operating point, especially for the compression stage. The increase in mass flow on the turbine generally requires to "open" the device used for boost pressure regulation (Variable Geometry Turbine (VGT) or wastegate), whatever the application. As a consequence, the effect on the expansion stage efficiency closely depends on the technology: in case of VGT, the efficiency is improved, but in case of wastegates it is the contrary.

To conclude this part, LP EGR has a great effect on pressure drops and temperature upstream compression stage, both having a negative effect on engine back pressure (LP EGR can improve engine back pressure only if the improvement in turbocharger efficiency compensates for all these losses). As a consequence, this increases the LP IMEP, and in so far as the IMEP should remain the same for all the simulations, the quantity of fuel injected increases as well. The main consequence is of course the increase of the Specific Fuel Consumption (SFC):

- another consequence may be the impossibility to reach the supercharging pressure target, to preserve the HP turbine 


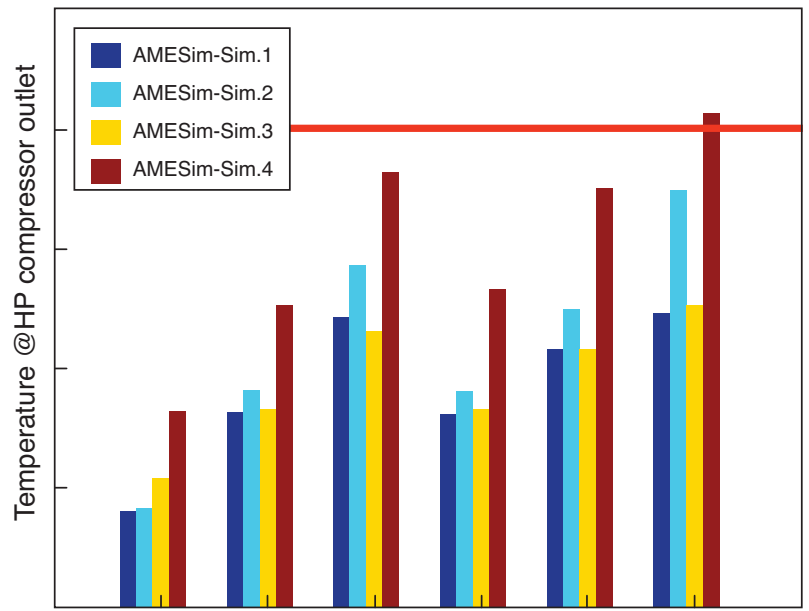

Point number

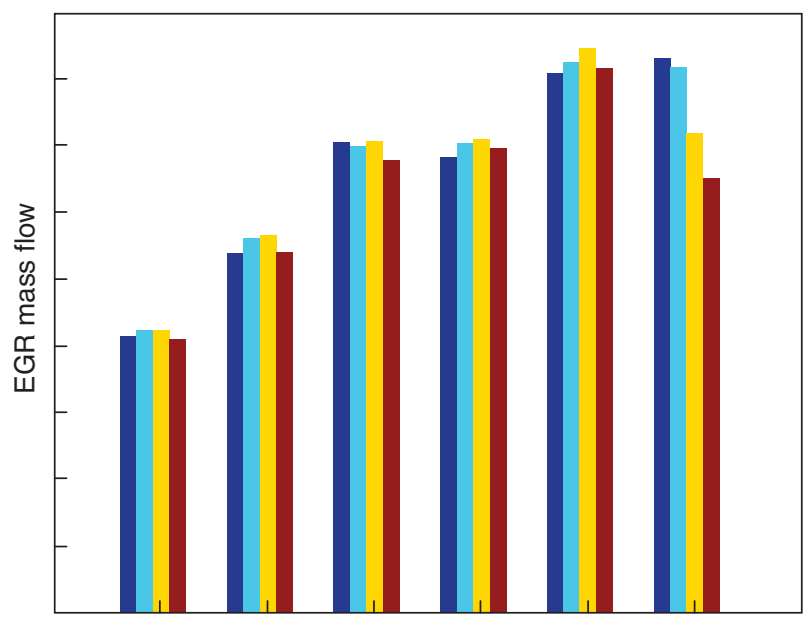

Point number

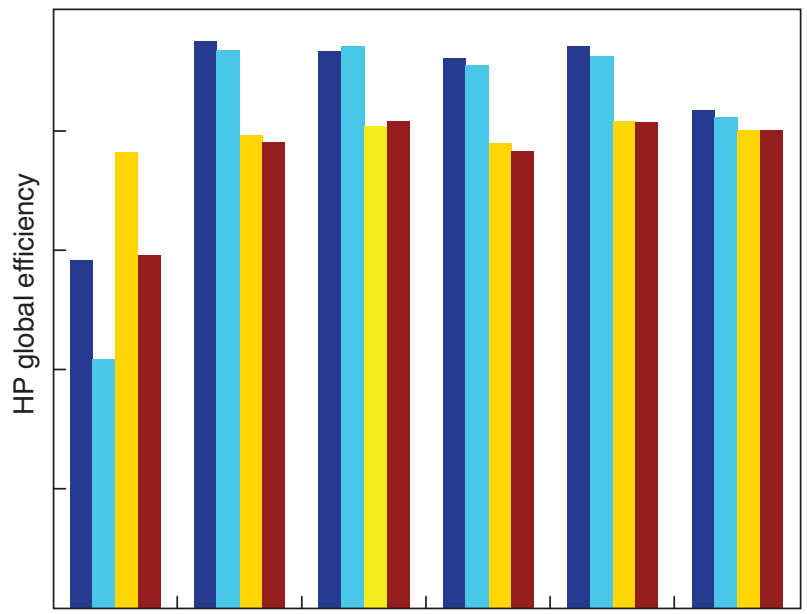

Point number

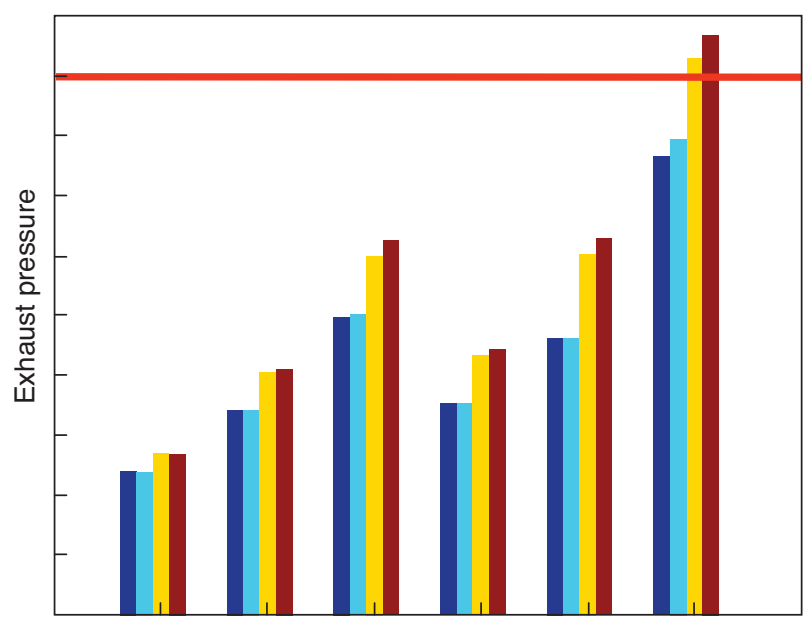

Point number

Figure 12

Relative comparison between simulation results on a the 6 steady state set points extracted from the EGR zone on: T@HP compressor downstream (top), HP turbine global efficiency (top right), EGR mass flow (bottom left) and exhaust pressure (bottom right).

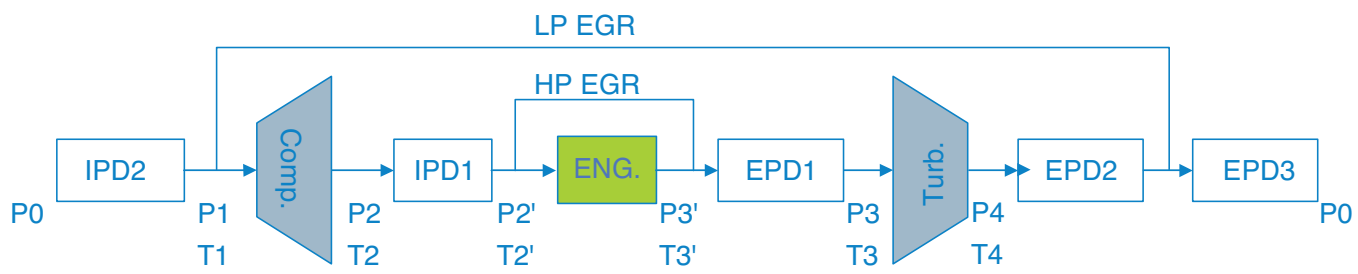

Figure 13

Schematic view of air and EGR loop. 
from a too high inlet pressure (represented by the red line in Fig. 12);

- another value that can be commented is the EGR mass flow. As observed on this figure, the EGR mass flow decreases for simulators with a LP EGR circuit. This decline is due to the increase of fuel quantity that compensates for the higher LP IMEP. As the simulations are made with a constant FAER, the EGR mass flow has to decrease. This has of course an impact on the engine pollutant emissions, although this is not directly represented by the simulator yet;

- finally, an additional remark can be made on the HP turbine global efficiency (see Eq. (5) for details about the calculation). Indeed, to be able to have fast response time during transient, the HP turbine should be small enough. However, in the case of a LP EGR circuit, the total mass flow passing through the HP turbine increases, which requires to open wider the HP turbine by-pass than with a HP EGR loop. As a consequence, even with a correct turbocharger mapping and thus a good intrinsic turbine efficiency, the global efficiency of the HP turbine can decrease in the case of LP EGR loop.

$$
\eta_{\text {HP.Turbine.global }}=\eta_{\text {HP.Turbine }} \times\left(\frac{Q_{\text {Useful }}}{Q_{\text {Useful }}+Q_{\text {bypassed }}}\right)
$$

If we plot in the HP compressor map, the different operating set points simulated, we can observe in Figure 14 that, due to the increase of the total mass coming through the HP compressor, the impact is the translation of the different set points to the right of the compressor map and as a consequence, depending on the turbocharger matching, this can have either a positive or a negative effect on the compressor efficiency. In this case, this has no real impact on the compressor efficiency, and thus, does not compensate for the negative effect of the LP EGR layout.

Finally, considering the optimal trade off between cost, performance and size of the system, two air path layouts have been selected to be more deeply studied in the second campaign:

- simulator 2: HP EGR circuit with only one HP air cooler,

- simulator 4: LP EGR circuit with only one HP air cooler.

\subsection{LP EGR Impact Study on Two Specific Layouts}

For this second numerical campaign, the two main objectives are the optimization of the cooler efficiencies (supercharging and EGR coolers) and the optimization of the settings of each set points. To that purpose, the two architectures have been compared on:

1. an EGR cooler efficiency variation;

2. their robustness to a variation of atmospheric conditions;
3. the maximum EGR mass flow possibility respecting a maximum temperature at HP compressor outlet (T@HPCO) and a maximum pressure at HP turbine inlet (P@HPTI) constraints with constant IMEP and supercharging targets (only simulator 4);

4. the effect on EGR mass flow for a supercharging pressure variation with constant FAER and IMEP targets (only simulator 4).

For tests (1) and (2), the main conclusions are:

- difficulties to reach the supercharging pressure target with the LP EGR circuit for atmospheric condition variations while respecting the constraints on the maximum HP compressor outlet temperature value and the maximum HP turbine inlet pressure value;

- difficulties to respect the EGR target for inefficient LP EGR cooler for the same reasons.

Both of these points show the importance of the cooling device for a TS Turbocharging architecture with a LP EGR circuit.

For test (3), in Figure 15, we can observe that according to simulation results, an EGR maximum value has been found for each set point thanks to LP EGR valve and exhaust throttle position variations. We can notice that, due to the slight slope of the curves, the EGR maximum value really needs to be decreased (set point 6 for instance), not to get higher than the maximum temperature at HP compressor outlet allowed (in black in Fig. 15).

Finally, for test (4), an optimum of the supercharging pressure target has been investigated for the three most

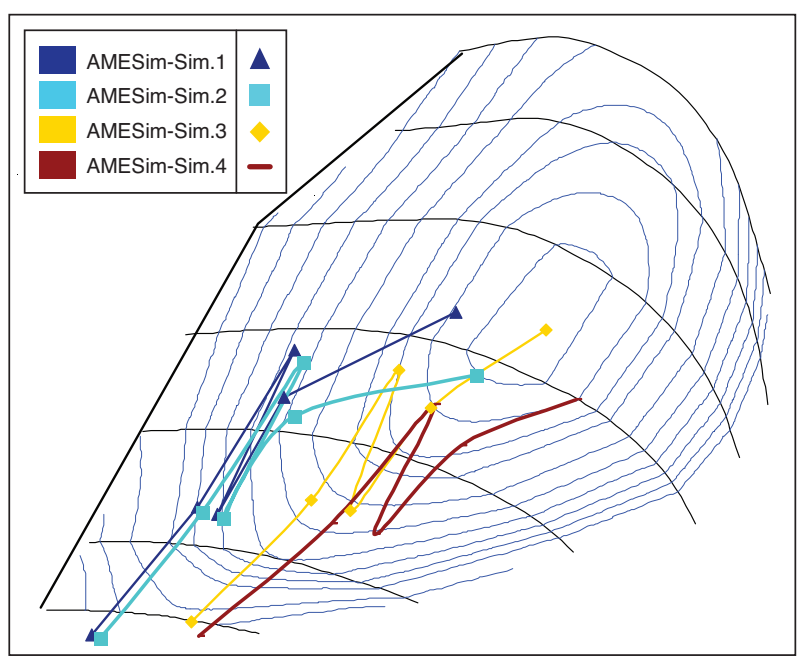

Figure 14

Comparison of simulation results for the 4 air path layouts in the HP compressor map. 
loaded set points, in order to respect the temperature at HP compressor outlet constraint while maintaining the FAER and the IMEP targets constant.

To that aim, three different values of supercharging pressure have been tested (see numbers 1, 2 and 3 in Fig. 16), and finally a fourth one has been found in order not to have a temperature at HP compressor outlet above the maximum value (black line in Fig. 16 on the right side). For this test, the loss of supercharging pressure to respect the maximum T@HPCO limit remains low (minus than 5\%), due to the more important slopes of the curves, which implies finally only a slight loss of EGR mass flow (Fig. 16 on the left side).

In this part, the impact of LP EGR in a TS Turbocharging environment has been studied by simulation. Thanks to that useful and reliable tool, this impact could have been studied without any bench tests, and have shown the difficulties of using LP EGR with two turbochargers: temperature at HP compressor outlet maximum value or pressure at HP turbine inlet maximum value leading to a possible increase in indicated specific fuel consumption. Finally, implementing a LP EGR circuit in a TS turbocharging environment has not only consequences on the system and its performances, but also on the strategies to control this system. Let's conclude this paper with an analyze of the impact of such a configuration of the air path on the control strategies, and the solution to that modification.

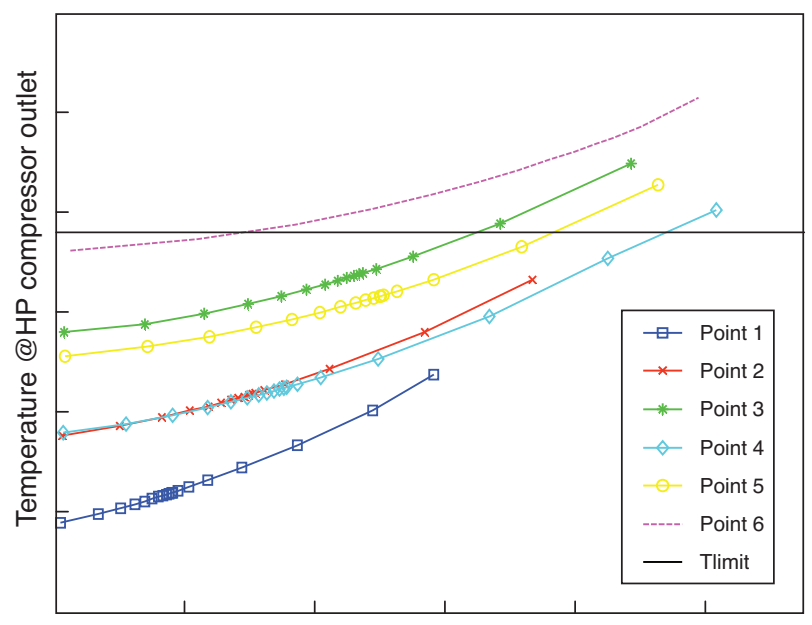

EGR mass flow

Figure 15

Evolution of the Temperature @HP compressor outlet versus EGR mass flow, for the 6 set points, during variations of the EGR valve and throttle positions (from $0 \%$ to $100 \%$ of closing).

\section{TWO-STAGE TURBOCHARGER ENGINE CONTROL DESIGN}

In the previous sections were presented an architecture study of two-stage turbocharger, and the impact of LP EGR on this system. In a similar approach, the section below exposes the specific issues of two-stage turbocharger control and a discussion on the impact of LP EGR on these issues.

\subsection{Turbocharger Control Issues}

The main objective of the engine control strategies is to produce a required mechanical torque on the engine shaft. This torque is released during the combustion of the mixture of air and fuel in the cylinder. On a Diesel engine, the combustion efficiency and the resulting pollutant emissions are linked with the mass and composition of gas aspirated by the cylinder. The engine gas mass flow depends on the intake manifold air density, while the intake gas composition depends on the balance between EGR flow and fresh air flow. Conventionally, the air path management structure considers two problems which are dealt with independently: the control of the fresh air mass flow via the actuation of the EGR valve, and the control of the intake manifold pressure via the turbocharger. In a single stage turbocharger system, the control strategy acts on the wastegate (WG) in order to follow a compressor downstream pressure set-point. Additionally, two constraints have to be respected for safety reasons: the turbocharger speed and the exhaust manifold pressure have to be maintained below maximum values. The control law must also be robust with respect to environmental conditions changes: the thermodynamic conditions at the boundaries of the system will affect its behaviour.

The goal of the project was to study the specific issues of TS turbocharging and design adequate control strategies. A major constraint was to do so without adding any new sensor, particularly between the two compressors or the two turbines (for additional details of this project, please refer to [19]).

\subsection{System Analysis}

Using the simulator as a virtual bench, several tests have been performed to study the impact of the LP waste gate position on the global system, and on the system dynamics.

The results presented in Figure 17 show load transient tests with two different positions of the LP waste gate (15\% and $85 \%$ of closing). The supercharging pressure is controlled by an action on the HP turbine by-pass. It can be noticed that a single stage controller can be applied on the HP stage, the LP stage being considered as a simple perturbation.

The first observation that can be made from these figures is that the HP turbocharger speed reaches high values in transient and stabilizes at lower values. The low time response of 

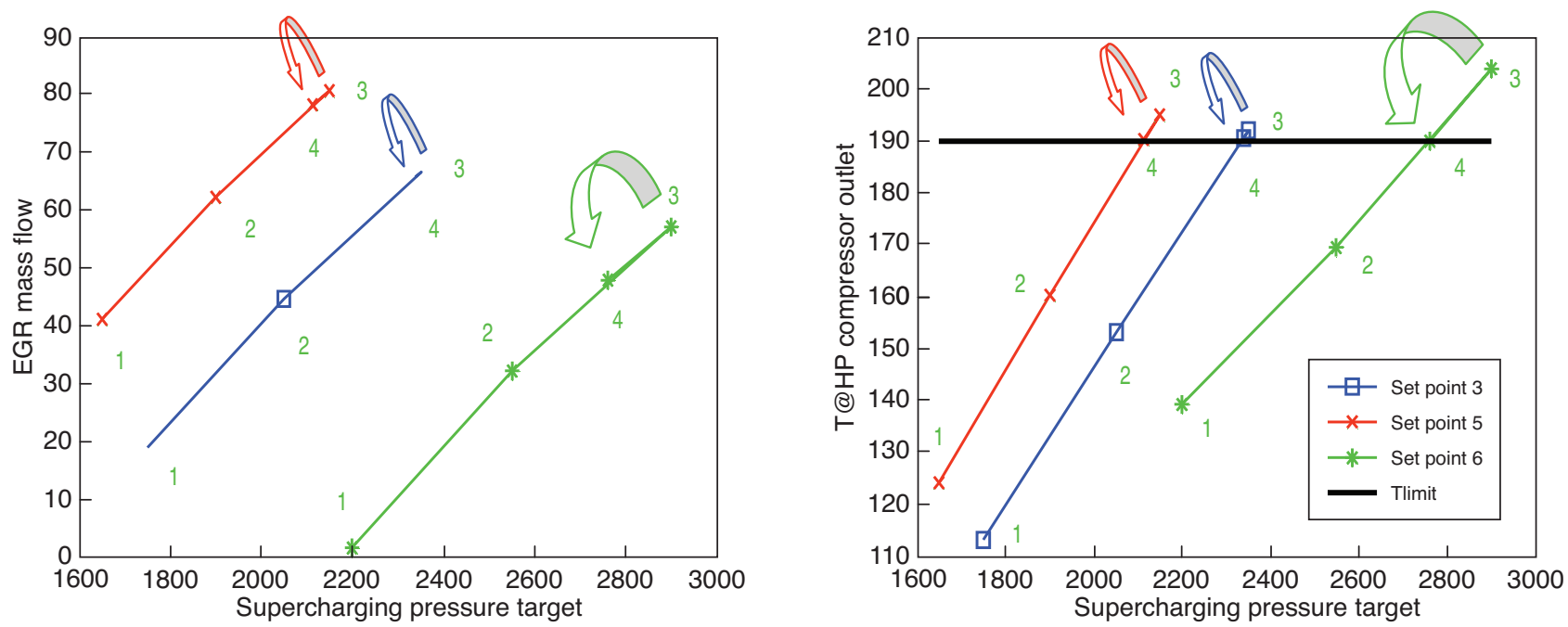

Figure 16

EGR mass flow (left) and temperature at HP compressor outlet versus supercharging pressure for the three most loaded set points.
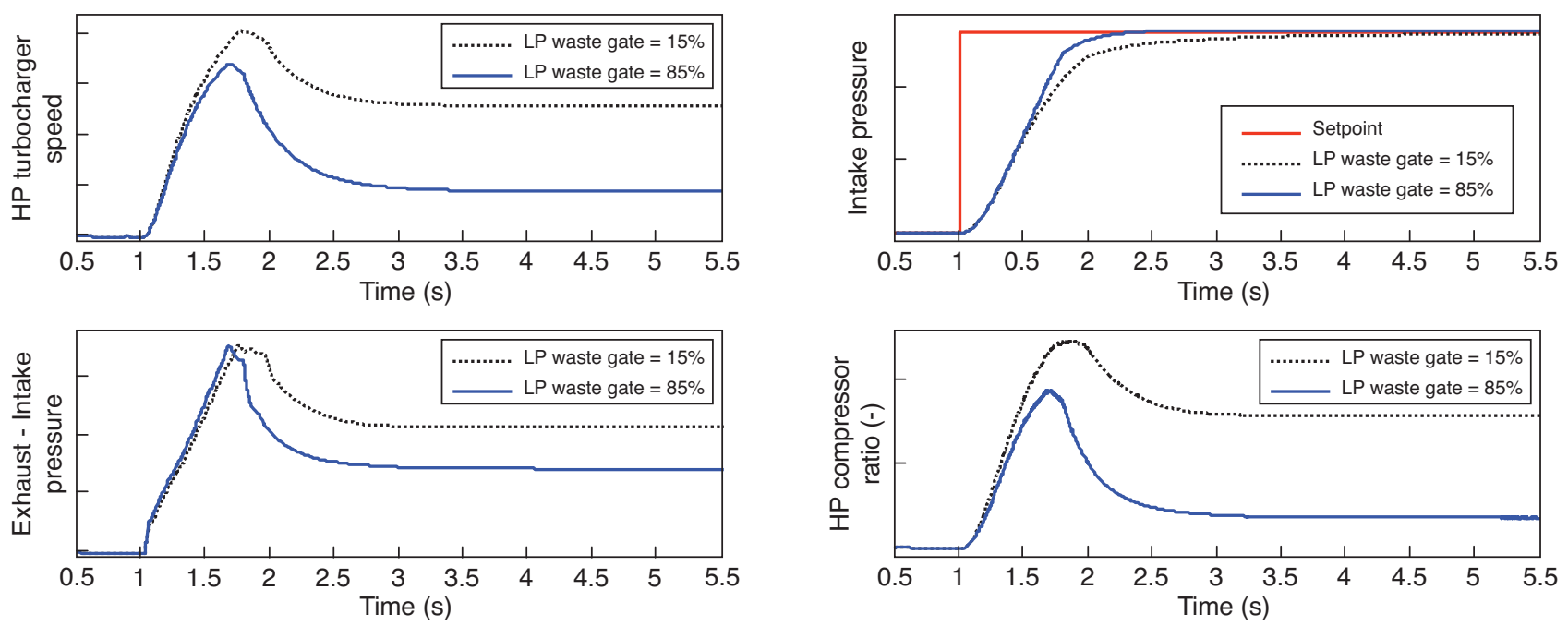

Figure 17

Effect of the variation of the LP waste gate opening on the intake pressure (top left), the HP compressor ratio (bottom left), the HP turbocharger speed (top right) and the difference of pressure between the exhaust and the intake (bottom right).

the LP turbocharger is compensated for by the faster HP stage. Because of this phenomenon, an overspeed problem can arise when the engine operates at high loads. An important fact is that the sensors available on the system do not give any information about the HP turbocharger speed. The HP compressor outlet pressure sensor provides a value that is the consequence of both compressions. They cannot be directly isolated from the sensors available.

Another important observation in Figure 17 is that a closed position of the LP wastegate is always beneficial to the system. Indeed, it makes the global system dynamics faster in transient (intake pressure and air flow rate), whereas in steady state it decreases the difference between the exhaust pressure and the intake pressure, reducing engine pumping losses.

In summary, this analysis leads to two important conclusions:

- when the HP turbocharger is used, the LP waste gate has to be closed;

- there is a risk of HP turbocharger overspeed in transient operations. 
Thanks to these first tests, the system operating modes could have been defined and have lead to the development of the control strategies, notably the transitions between the different operating modes:

- LP operating mode: in the LP turbocharger mode, the HP waste gate is opened, the HP compressor by-pass is opened (the air flow does not go through the HP compressor) and the LP wastegate controls the exhaust energy. In this mode, only the LP turbocharger provides compression work. It corresponds to high engine speed and low load;

- HP operating mode: In HP turbocharger mode, the LP waste gate is closed, the HP compressor by-pass is closed (all the air flow goes through the HP compressor) and the HP waste gate controls the boost pressure. The LP stage is considered as a simple perturbation. In this mode both turbocharger stages provide compression work. It corresponds to low engine speed and high load. In this mode, there is a risk of HP turbocharger overspeed. This risk is particularly important with a TS turbocharger because the HP turbocharger is mapped in order to improve the performance at low speed and thus accelerates the system in transient;

- Transient HP mode: Figure 18 represents, in the engine speed versus load map, the operating range that can be reached by each turbocharger, taking into account the constraints due to surge, choke and overspeed. There is an intermediate zone in which both turbochargers can operate. Since the LP turbocharger can provide the required compression work while generating less pumping losses, it is preferable to use it in steady state. The HP turbocharger can be used in transient to speed up the intake pressure dynamics.

\subsection{TS Turbocharger Control Development}

Following the analysis exposed in the previous section, the control strategies for the HP turbocharger when operating in HP mode can be similar to the ones used for single stage turbochargers, except that the thermodynamic conditions upstream and downstream the system must be estimated. This task is performed by a simplified model of the LP turbocharger. The details of the structure of the strategies designed in this project can be found in [19]. The LP turbocharger estimator is crucial for the performance of the controller and for maintaining the HP turbocharger below its mechanical limits. A schematics of the estimator is shown in Figure 19. It is based on the power balance on the turbocharger shaft:

$$
P_{t}-P_{c}=J \cdot N_{t} \cdot \frac{d N_{t}}{d t}
$$

where $J$ is the moment of inertia of the rotating parts.

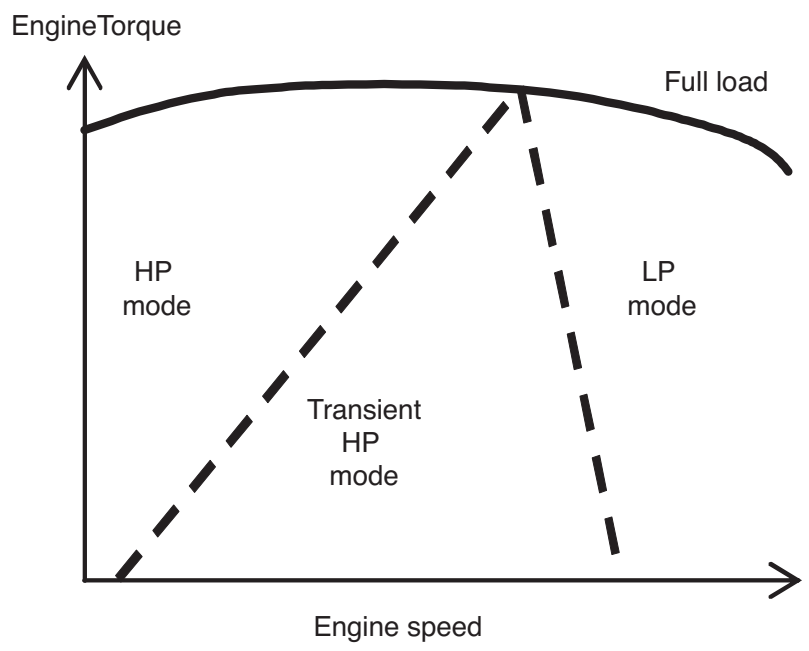

Figure 18

The operating modes of the Two- stage turbocharger.

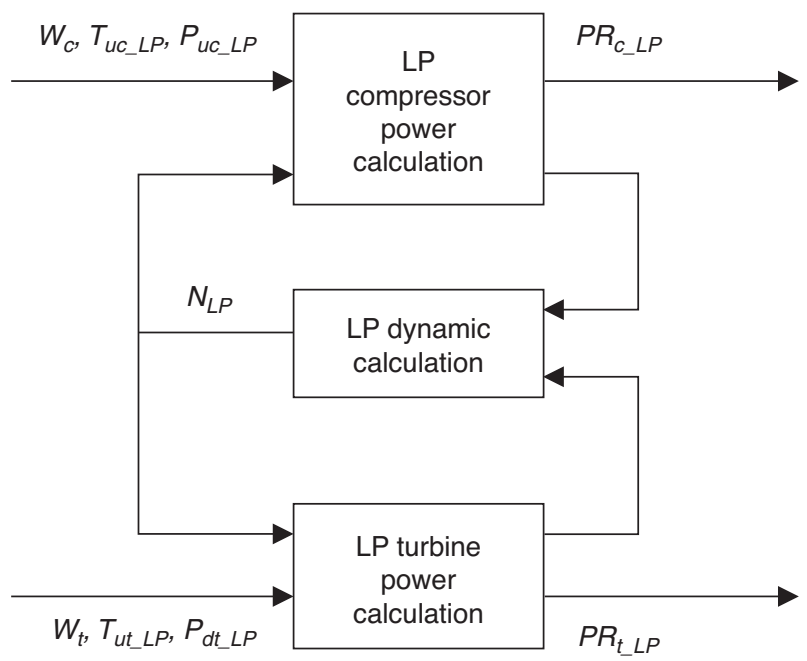

Figure 19

Description of the LP estimator.

The power developed by the turbine $P_{t}$ and the power required to drive the compressor $P_{c}$ can be expressed as:

$$
P_{t}=W_{t} \cdot C_{p} \cdot \eta_{t} \cdot T_{u t} \cdot\left[1-\left(\frac{1}{P R_{t}}\right)^{\frac{\gamma-1}{\gamma}}\right]
$$

where $P R_{t}$ is the turbine pressure ratio,

$$
P_{c}=W_{c} \cdot C_{p} \cdot \frac{1}{\eta_{c}} \cdot T_{u c} \cdot\left[\left(P R_{c}\right)^{\frac{\gamma-1}{\gamma}}-1\right]
$$

where $P R_{c}$ is the compressor pressure ratio. 
The inputs of this estimator are:

- mass air flow (measured): $W_{c}$ and $W_{i}$;

- temperature and pressure upstream the LP compressor (measured): $T_{u c_{-} L P}, P_{u c_{-} L P}$;

- pressure downstream the LP turbine (measured): $P_{d t L P}$;

- temperature before the LP turbine (estimated): $T_{u t \_L P}$.

Once an estimation of the pressures upstream the HP compressor and downstream the HP turbine is available, the HP turbocharger system can be isolated from the LP turbocharger dynamics. The final structure of the controller designed for TS turbochargers can be similar to a single stage turbocharger control structure (see [19] for detailed justifications). A scheme of the obtained strategy is represented in Figure 20.

This strategy answers to the requirements described in Section 4.1 mostly because it uses variables related closely to the state of the turbocharger: compressor and turbine pressure ratios. The setpoints and feed forward values are based on the outputs of the LP turbocharger estimator. The HP turbocharger speed limitation is ensured by a limitation of the HP compression ratio.

\subsection{Development Approach Based on Simulation}

The strategies have been developed following the approach which consists in standard tests that were performed on the simulator, providing references for a comparison between different strategies and calibrations. The different tests used were:

1. steady state tests, for the determination of open loop feed forward terms,

2. transient tests, for an evaluation of the strategy performances in terms of response time, overshoot and stability,

3. failure simulation, for the validation of diagnosis strategy: on the simulator, it is possible to represent leakages at various locations along the intake and exhaust circuits and to verify that the strategies can deal with those problems (detection and adaptation),

4. environmental conditions variations: it is possible to simulate a change in atmospheric pressure and temperature, or an increase of the after-treatment system back pressure (particulate filter loading...), and to verify that the control strategies work well in those conditions (in steady state and in transient),

5. component dispersion simulation: an important requirement of the strategies is the robustness against production dispersions (sensors, actuators, components); the performances of the control algorithms were verified in transient while accounting for these dispersions.

Even if some of those tests $(1,2)$ could have been performed on a real test bed, the use of simulation has provided a way of accelerating and facilitating the development

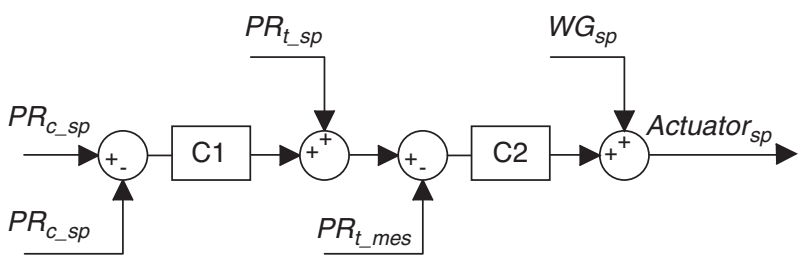

Figure 20

TS turbocharger control structure.

process. However, in some cases, the tests would not have been possible on a real engine: it would rather have required the damaging of some components (3), or a very high number of tests $(4,5)$. As a matter of fact, the use of simulation tools for those tests is not only necessary, but also provides information that would not be available otherwise.

The following figures show examples of the tests performed by co-simulation in order to validate the limitation of the HP turbocharger speed in transient. AMESim is coupled to Matlab Simulink to perform the simulations. Figure 21 shows the HP turbocharger with and without the limitation strategy, and the impact on the intake pressure during a load transient at a constant engine speed (2000 rpm). This transient shows that the HP turbocharger speed remains under the safety limitation (280000 rpm) when the strategy is active.

\subsection{Impact of LP EGR on the Two-Stage Turbocharger Control Strategies}

The purpose of this section is to give a brief discussion of the impact of LP EGR on TS turbocharger control strategies, in order to illustrate how the simulators developed can help studying this kind of aspects.

When operating with HP EGR, the gas mass flow rate through the compressors and turbines depend on the EGR quantity but is measured by a sensor located upstream the air system. This measurement is used as an input in the control strategies, and in particular LP turbocharger estimator. In the case of LP EGR, the flow rate through the compressors is the sum of the fresh air flow (measured) and the EGR flow (unknown). In the structure described above, the two major impacts of LP EGR on TS turbocharger control strategies are therefore:

- impact on the LP turbocharger estimator;

- impact on the feed forwards (because the compressor air mass flow is an input in this part).

Both impacts require an estimation of the gas mass flow through the compressors and turbines. Once this value is available, the control strategies can use the same inputs as in the HP EGR case. A very simple modification can take account of these phenomena. The air mass flow through the compressors is equal to the engine mass flow, deduced 

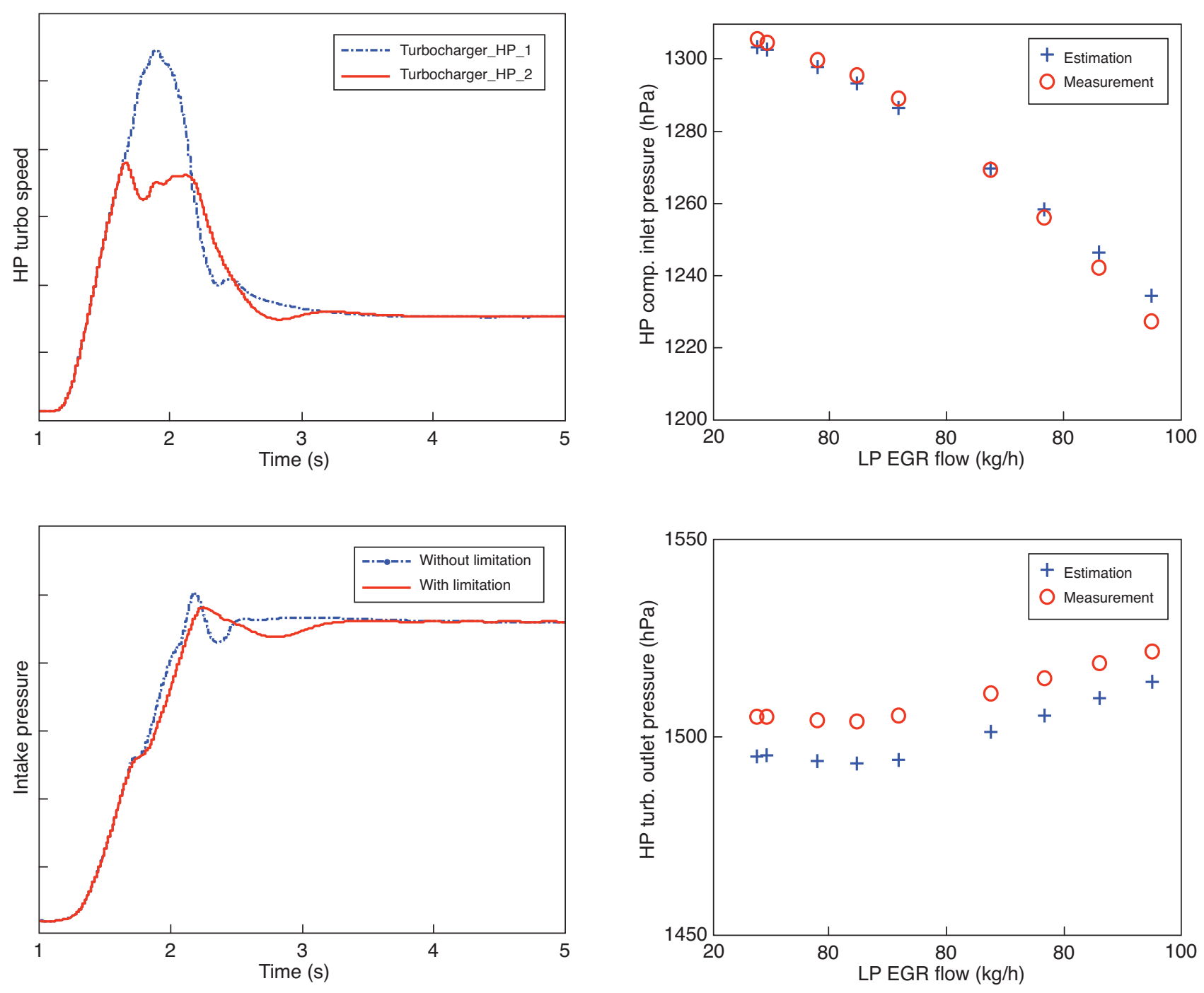

Figure 21

Co-simulation results for a load transient at $2000 \mathrm{rpm}$ with and without a HP turbocharger speed limitation strategy: HP turbocharger speed (left) and intake pressure (right).

Figure 22

Validation of the LP turbocharger estimator in case of LP EGR.

from an estimation of the volumetric efficiency (see [20] and Eq. 9):

$$
Q_{\text {eng }}=\frac{\eta_{v o l} \cdot V_{c y l} \cdot P_{i n} \cdot N_{e}}{30 \cdot R \cdot T_{\text {in }}}
$$

As explained in the previous section, the crucial part of the strategies is to isolate the HP turbocharger from the system other dynamics so that it is possible to consider it as a single stage turbocharger. The LP turbocharger estimation is therefore the key issue. Figure 22 shows validation results obtained in simulation of the estimator thus adapted. It represents a comparison between the pressures upstream the HP compressor and downstream the HP turbine obtained in the simulator and estimated in the control strategies, for different
LP EGR flow at a given engine operating point. The difference between estimation and measurement is kept small, showing that the LP turbocharger estimator takes well into account the impact of the LP EGR. When this is ensured, the assumption that the HP turbocharger can be controlled as a single stage turbocharger remains valid.

\section{CONCLUSION}

This paper demonstrates, thanks to the help of engine system simulation in the AMESim environment, the impact of LP EGR on the engine performances in the specific case of a Two-Stage Turbocharged Diesel engine and the necessary modifications of the control through the LP turbocharger 
estimator. Allowing to make quickly and easily any modifications of the air path and then to simulate a lot a tests (not always feasible on a real test bed), the importance of engine system simulation in such kind of study is also depicted. Finally, through this study on different air path layouts, the interest of using simulation for control purpose is confirmed and a solution to adapt the control strategies in the case of a LP EGR circuit is proposed and validated on simulation results.

\section{ACKNOWLEDGEMENTS}

The authors want to thank O. Grondin for his valuable contribution to this paper.

\section{REFERENCES}

1 Christmann R., Schmalzl, H.-P., Schmitt F., Schwarz A. (2005) Regulated 2-Stage Turbocharging, MTZ Worldwide edition, 66, 1 .

2 Schwarzmann D., Nitsche R., Lunze J. (2006) Modelling of the air-system of a two-stage turbocharger passenger car diesel engine, Proceedings 5th MATHMOD Vienna, February 2006.

3 Steinparzer F., Kratochwill H., Mattes W., Steinmayr T. (2006) The New BMW Inline Six Cylinder Diesel Engine with Dual Stage Turbocharging - Best in its Class in Efficient Dynamic Steinparzer F. and co., BMW Motoren GmbH", 15. Aachener Kolloquium Fahrzeug- und Motorentechnik 2006.

4 Saulnier S., Guilain S. (2004) Computational Study of Diesel Engine Downsizing using two-stage turbocharging, SAE paper 2004-01-0929.

5 Portalier J., Blanc J.C., Garnier F., Hoffmann N., Schorn N., Kindl H., Galindo J., Jeckel D., Uhl P., Laissus, J.-J. (2006) Twin Turbo Boosting System Design for the New Generation of PSA 2,2 Liter HDI Diesel Engines, THIESEL 2006 Conference on Thermo- and Fluid Dynamic Processes in Diesel Engines 2006.

6 Beatrice C., Avolio G., Del Giacomo N., Guido Ch., Lazarro M. (2008) The Effect of "Clean and Cold" EGR on the Improvement of Low-Temperature Combustion Performance in a Single-Cylinder Research Diesel Engine, SAE paper 2008-010650 .

7 Van Aken M., Willens F., De Jong D.J. (2007) Appliance of High EGR Rates With a Short and Long Route EGR System on a Heavy-Duty Diesel Engine, SAE paper 2007-01-0906.
8 Vítek O., Macek J., Polášek M., Schemerbeck S., Kammerdiener T. (2008) Comparison of Different EGR Solutions, SAE paper 2008-01-0206.

9 Luján J.M., Pla B., Moroz S., Bourgoin G. (2008) Effect of Low Pressure EGR on gas exchange processes and turbocharging of a HSDI engine, THIESEL 2008 Conference on Thermo- and Fluid Dynamic Processes in Diesel Engines 2008.

10 Bression G., Pacaud P., Soleri D., Cessou J., Azoulay D., Lawrence N., Doradoux L., Guerrassi N. (2008) Comparative Study in LTC Combustion between a Short HP EGR Loop without Cooler and a Variable Lift and Duration System, Aachener Kolloquium Fahrzeug- und Motorentechnik 2008.

11 Albrecht A., Grondin O., Le Berr F., Le Solliec G. (2007) Towards a stronger simulation support for engine control design: a methodological point of view, Oil Gas Sci. Technol. 62, 4. http://ogst.ifp.fr/.

12 Le Berr F., Alix G., Richard S., Lafossas F.A., Font G., Corde G., Albrecht A. (2008) Powertrain Simulation tools and application to the development of a SI engine concept car, SAE paper 2008-01-0356.

13 Gautier P., Albrecht A., Chasse A., Moulin P., Fontvieille L., Guinois A., Doléac L. (2008) A new simulation step towards virtual bench through the challenging case of two-stage turbocharger Diesel engine control design, SAE paper 2008-010355 .

14 Chmela F., Orthaber G. (1999) Rate of heat release prediction for direct injection Diesel engines based on purely mixing controlled combustion, SAE paper 1999-01-0186.

15 Albrecht A., Chauvin J., Lafossas F.-A., Potteau S., Corde G. (2006) Development of Highly Premixed Combustion Diesel Engine Model: From Simulation to Control Design, SAE paper 2006-01-1072.

16 http://www.lmsintl.com/imagine-amesim-1-d-multi-domainsystem-simulation, LMS - IMAGINE.

17 Menegazzi P., Aubret P., Vernhes P.L. (2004) Conventional and Hybrid Vehicle Emission, Fuel Economy and Performance Analysis System Simulation, FISITA 2004, Barcelona, Spain.

18 Lafossas F.A., Colin O., Le Berr F., Menegazzi P. (2005) Application of a New 1D Combustion Model to Gasoline Transient Engine Operation, SAE paper 2005-01-2107.

19 Chasse A., Moulin P., Gautier P., Albrecht A., Fontvieille L., Guinois A., Doléac L. (2008) Double Stage Turbocharger Control Strategies Development, SAE paper 2008-01-0988.

20 Heywood J.B. (1988) Internal Combustion Engine Fundamentals, McGraw Hill.

Final manuscript received in July 2008 Published online in May 2009 or distributed for profit or commercial advantage and that copies bear this notice and the full citation on the first page. Copyrights for components of this work owned by others than IFP must be honored. Abstracting with credit is permitted. To copy otherwise, to republish, to post on servers, or to redistribute to lists, requires prior specific permission and/or a fee: Request permission from Documentation, Institut français du pétrole, fax. +33147527078 , or revueogst@ifp.fr. 